\title{
Molecular characterisation of the STRUBBELIG-RECEPTOR FAMILY of genes encoding putative leucine-rich repeat receptor-like kinases in Arabidopsis thaliana
}

\author{
Banu Eyüboglu ${ }^{1}$, Karen Pfister $^{1}$, Georg Haberer ${ }^{2}$, David Chevalier ${ }^{1,3}$, \\ Angelika Fuchs ${ }^{1}$, Klaus FX Mayer ${ }^{2}$ and Kay Schneitz*1
}

\begin{abstract}
Address: ${ }^{1}$ Plant Developmental Biology, Science Center Weihenstephan, Technical University Munich, Am Hochanger 4, 85354 Freising, Germany, ${ }^{2}$ MIPS, Institute for Bioinformatics, GSF National Research Center for Environment and Health, Ingoldstädter Landstrasse 1, 85764 Neuherberg, Germany and ${ }^{3}$ Division of Biological Sciences, 304 Life Sciences Center, University of Missouri, Columbia, MO 65211, USA
\end{abstract}

Email: Banu Eyüboglu - banu@wzw.tum.de; Karen Pfister - karen.pfister@wzw.tum.de; Georg Haberer - g.haberer@gsf.de; David Chevalier - chevalierd@missouri.edu; Angelika Fuchs - angelika.fuchs@gmx.net; Klaus FX Mayer - kmayer@gsf.de;

Kay Schneitz* - schneitz@wzw.tum.de

* Corresponding author

Published: 30 March 2007

BMC Plant Biology 2007, 7:16 doi:10.1186/147I-2229-7-16
Received: 21 September 2006

Accepted: 30 March 2007

This article is available from: http://www.biomedcentral.com/I47/-2229/7/16

(c) 2007 Eyüboglu et al; licensee BioMed Central Ltd.

This is an Open Access article distributed under the terms of the Creative Commons Attribution License (http://creativecommons.org/licenses/by/2.0), which permits unrestricted use, distribution, and reproduction in any medium, provided the original work is properly cited.

\begin{abstract}
Background: Receptor-like kinases are a prominent class of surface receptors that regulate many aspects of the plant life cycle. Despite recent advances the function of most receptor-like kinases remains elusive. Therefore, it is paramount to investigate these receptors. The task is complicated by the fact that receptor-like kinases belong to a large monophyletic family with many sub-clades. In general, functional analysis of gene family members by reverse genetics is often obscured by several issues, such as redundancy, subtle or difficult to detect phenotypes in mutants, or by decision problems regarding suitable biological and biochemical assays. Therefore, in many cases additional strategies have to be employed to allow inference of hypotheses regarding gene function.
\end{abstract}

Results: We approached the function of genes encoding the nine-member STRUBBELIG-RECEPTOR FAMILY (SRF) class of putative leucine-rich repeat receptor-like kinases. Sequence comparisons show overall conservation but also divergence in predicted functional domains among SRF proteins. Interestingly, SRFI undergoes differential splicing. As a result, SRFI is predicted to exist in a standard receptor configuration and in a membrane-anchored receptor-like version that lacks most of the intracellular domain. Furthermore, SRFI is characterised by a high degree of polymorphism between the Ler and Col accessions. Two independent T-DNA-based srf4 mutants showed smaller leaves while 35S.::SRF4 plants displayed enlarged leaves. This is in addition to the strubbelig phenotype which has been described before. Additional single and several key double mutant combinations did not reveal obvious mutant phenotypes. Ectopic expression of several SRF genes, using the $35 S$ promoter, resulted in male sterility. To gain possible insights into SRF gene function we employed a computational analysis of publicly available microarray data. We performed global expression profiling, coexpression analysis, and an analysis of the enrichment of gene ontology terms among coexpressed genes. The bioinformatic analyses raise the possibility that some SRF genes affect different aspects of cell wall biology. The results also indicate that redundancy is a minor aspect of the $S R F$ family.

Conclusion: The results provide evidence that SRF4 is a positive regulator of leaf size. In addition, they suggest that the SRF family is characterised by functional diversity and that some SRF genes may function in cell wall biology. They also indicate that complementing reverse genetics with bioinformatical data mining of genome-wide expression data aids in inferring hypotheses on possible functions for members of a gene family. 


\section{Background}

Receptor-like kinases (RLKs) constitute a prominent class of receptors that transmit a signal across a membrane. The years since the first isolation of a plant RLK [1] have witnessed a great increase in knowledge regarding the function of plant RLKs. RLKs are required for cellular communication in many processes during the plant's life cycle, regulating aspects of development, defense, and physiology [2-6]. The importance of RLKs in plants is emphasized by the observation that RLKs constitute about $2.5 \%$ of the Arabidopsis protein coding sequences $[7,8]$. Moreover, greater than 200 RLKs belong to the leucinerich repeat (LRR) class of RLKs typified by varying numbers of LRRs in their extracellular domain. LRRs are involved in protein-protein interactions and are found in numerous types of proteins [9]. Presently, the biological roles of only a handful of RLKs are known. Thus, one important task consists of gaining information about the functions of the remaining plant RLKs.

The functional analysis of genes encoding RLKs is often complicated due to redundancy issues. For example, during early anther development there are repeated requirements for position-dependent intercellular signaling events mediated by discrete sets of redundantly acting LRR-RLKs. The development of the tapetum and the differentiation of microspores depend on the function of several LRR-RLK genes. Analysis of mutations in a single gene, encoding the LRR-X class LRR-RLK EXCESS MICROSPOROCYTES 1/EXTRA SPOROGENOUS CELLS (EXS/ EMS) $[10,11]$ revealed a role for EXS/EMS in these aspects of anther development. Anthers of exs/ems mutants fail to form a tapetum and show an increased number of aberrantly developing pollen mother cells. Further, SOMATIC EMBRYOGENESIS RECEPTOR KINASE 1 (SERK1) and SERK2 encode two homologous LRR-RLKs of the LRR-II class $[12,13]$ that are coexpressed during early anther development. While serk1 and serk2 single mutants both exhibit a wild-type anther morphology, the serk1 serk2 double mutants resemble exs/ems single mutants [12,13].

This finding suggests functionally redundant roles for SERK1 and SERK2 in processes that also depend on EXS/ EMS function. Interestingly, translational fusions of SERK1 and SERK2 to variants of green fluorescent protein can form homo- and heterodimers in a cell culture system, indicating that SERK1/SERK2 may act in the same protein complex [12]. Another early aspect of anther development is the asymmetric cell division of archesporial cells and the differentiation of primary parietal and primary sporogenous cells. This process is effected by BARELY ANY MERISTEM (BAM1) and BAM2 [14]. BAM1 and BAM2 are members of a gene family encoding LRR-RLKs, that, in addition to BAM1 and BAM2, includes CLAVATA1 (CLV1) and BAM3 [15].
The examples described above represent relatively straightforward cases of functional redundancy, where very similar genes are co-expressed in the same tissue and are likely to functionally substitute for each other. Conversely, there are also known instances where a diversification of function has taken place in evolution, largely through alterations in gene expression patterns between closely related LRR-RLK genes. This can result in a combination of partially overlapping and partially separate functions.

For example, signal transduction involving brassinosteroids (BRs) plays an important role in cell elongation and differentiation $[16,17]$. BRASSINOSTEROID INSENSITIVE1 (BRI1) encodes a LRR-RLK that constitutes a key component of a BR receptor complex [18-20]. The Arabidopsis genome contains several close relatives of BRI1: the BRI1-like genes BRL1, BRL3 and VASCULAR HIGHWAY1 (VH1)/BRL2 [18,21-23]. VH1 does not bind BR but is required for the maintenance of provascular differentiation $[21,22]$. BRI1, BRL1 and BRL3 encode proteins that share the capacity to bind BR $[20,22]$. The three genes, however, differ in their expression patterns and there is a shift of emphasis regarding their functions. While BRI1 is expressed in a broad fashion, BRL1 and $B R L 3$ are predominantly expressed in a complementary pattern in vascular tissue $[18,20,22-24]$. In accordance with its expression pattern, BRI 1 exerts a broad function in cell elongation and differentiation, which includes the differentiation of vascular tissue. BRL1 and BRL3 can fully substitute for BRI1 [22,23]. However, BRL1 and BRL3 are mainly required for vascular differentiation, whereby synergistic interactions of BRI1 with BRL1 and BRL3 are required for regular vascular development [22]. A similarly complex behavior is exhibited by the small group of genes encoding ERECTA (ER) and ERECTA-LIKE1 (ERL1) and ERL2 LRR-RLKs that regulate organ size and stomata development [25-27].

The LRR-class of RLKs has been subdivided into several classes (LRRI-LRR-XIII) [7]. We are interested in the LRRV/STRUBBELIG-RECEPTOR FAMILY (SRF) gene family encoding putative LRR-RLKs [7]. This monophyletic family is represented by STRUBBELIG (SUB) and eight additional members. SUB was originally identified in a screen for mutants with a defect in ovule development [28]. In more recent work it was shown that SUB encodes a putative LRR-RLK of central importance to the plant as it affects cellular morphogenesis in a number of different organs [29]. In particular, SUB is required for the orientation of the cell division plane and the control of cell number, cell size and cell shape. Furthermore, $S U B$, also known as SCRAMBLED (SCM), affects root hair specification [30,31]. A combination of biochemical and genetic evidence suggests that phosphotransfer activity of the 
kinase domain is not essential for SUB protein function [29]. Thus, SUB is likely to represent an atypical or "dead" RLK [32]. In this paper we report on the initial molecular and functional characterisation of the other members of the $S R F$ gene family.

\section{Results}

The LRR-V/SRF gene family encodes putative LRR-RLKs

SUB belongs to LRR-V family of Arabidopsis LRR-RLKs [7]. Further database searches failed to identify additional family members in Arabidopsis. Thus, the LRR-V family encompasses 9 different representatives encoded by genes that are located throughout the genome. We coined the term STRUBBELIG-RECEPTOR FAMILY (SRF) and named the individual family members SRF1 to SRF8 [33]. SUB would be SRF9 but retained its original name (Table 1). $S R F$ members also relate to the ltk gene family of unknown function from corn [34]. We compared the genomic coordinates of $S R F$ genes to investigate whether some pairs are located in segments derived from the youngest large-scale duplication event in Arabidopsis [35]. The pairs SRF1/SRF3, SRF4/SRF5 and SRF6/SRF7 were found as segmentally duplicated pairs while $S U B$, SRF2 and SRF8 were not located in duplicated regions. We isolated tentative full-length cDNAs of all members (see Methods) to characterize the intron-exon organisation of the SRF genes (Figure 1). During this work it became clear that all $S R F$ genes carried incorrect annotations in the Arabidopsis database. The reannotation information was submitted to the MIPS Arabidopsis database [36] and to TAIR [37].

With one distinction regarding SRF1 (see below), conceptual translation of the SRF genes suggests that they encode putative LRR-RLKs with an extra-cellular domain (ECD), a transmembrane domain (TM), an intracellular juxtamembrane domain (JM), an intracellular catalytic or kinase domain (CD), and in some cases, an extended C-terminus (Figures 2, 3A, 3B). At the amino acid level, predicted SRF members exhibit variable degrees of conservation ranging from $32.5 \%$ identity to $77.9 \%$ identity (Table 2 ) and fall into distinct subclades (Figure 4) [7]. The predicted SRF proteins share an overall domain organisation. The ECDs of the LRR-V family are characterised by a stretch of 59 to 60 conserved residues representing the SUB-domain and located just N-terminal to six LRRs [29]. The role of the SUB domain is unknown. At least for SUB, however, the SUB-domain appears to be functionally relevant as the $s u b-3$ allele results in an amino acid substitution at a conserved position in the SUB domain (V64M) [29].

The part of the ECD region that is flanked by the last LRRrepeat and the TM domain varies between the different SRF members. In case of SRF2 this region encompasses 67 residues (residues 228-294). Several SRF members fea- ture particular regional distinctions in the central part of this domain (roughly residues 245 to 270 of SRF2). SRF1, SRF3, and SUB carry insertions in this region ranging from eight residues (SRF1) to 44 residues (SUB) while SRF4 and SRF5 each feature an identical deletion of 14 amino acids. This central part is also enriched in proline residues, particularly in SUB but also in SRF1, SRF3, SRF6 and SRF7. In the case of SRF3 an additional proline-rich domain is also located before the kinase domain.

The JM is variable among the family members. The kinase domains of the SRF proteins have the hallmarks of typical protein kinases [38] (Figure 3B). A more detailed comparison of the kinase domains, however, indicates that there are notable differences in a stretch of residues flanked by kinase subdomains II and III, a region known to be variable betweeen different protein kinases [38,39], and in the activation segment. The kinase subdomains II and III are required for the binding of ATP and the activation segment is important for substrate binding $[40,41]$. SUB, SRF2 and SRF8 feature unique activation segment sequences. This domain is more conserved within the SRF1/3, SRF6/7, and to some extent SRF4/5, pairs. The activation segment sequences of the individual pairs, however, are again distinct from each other and the other LRRV family activation segment sequences. This finding indicates that there may be considerable diversity in substrate recognition among family members, and therefore diversity in function. The findings also leave open possible redundant functions of members of the three more conserved pairs (but see also below).

The carboxy-termini (C-termini) of the SRF members represent another domain of diversity. SRF2 has the longest C-terminus (40 residues) while SUB and SRF4 lack such C-termini. In contrast, SRF5, the closest homolog of SRF4, features a 23 residue extension. Furthermore, only the first 13 amino acids of the SRF6 and SRF7 extensions are conserved. Interestingly, distinct serines in the C-termini of SRF7 and SRF8 (Figure 3B) are phosphorylated in an Arabidopsis suspension culture system [42].

\section{SRF I undergoes differential splicing}

During the full-length cDNA isolation experiments we noticed that $S R F 1$ undergoes differential splicing resulting in two mRNA species: one lacks intron 10 (SRF1A), the other carries intron 10 (SRF1B) (Figure 1). The differential splicing event occurs in both Ler and Col indicating that it is not related to the observed SRF1 Ler/Col polymorphisms (see below). Differential splicing of SRF1 was observed in all tissues tested. We could not detect splicing variants for the other $S R F$ members in RT-PCR experiments using primer pairs flanking the equivalent intron. Full-length SRF1A and SRF1B CDNA species were generated from RNA isolated from stage 1-12 flowers (see 
Table I: Accession codes of the SRF family members

\begin{tabular}{|c|c|c|}
\hline Gene & AGI Code & GenBank Accession \\
\hline SUB (SRF9) & Atlg 11130 & AF399923 \\
\hline SRFIA (Col) & At2g20850 & AY518286 \\
\hline SRFIB Col & & DQ914918 \\
\hline SRFIA Ler & & DQ914919 \\
\hline SRFIB Ler & & $\overline{\mathrm{DQ} 914920}$ \\
\hline SRF2 & At5g06820 & AY518287 \\
\hline SRF3 & At4g03390 & AY518288 \\
\hline SRF4 & At3gl3065 & AY518289 \\
\hline SRF5 & Atlg78980 & AY518290 \\
\hline SRF6 & Atlg53730 & AY518291 \\
\hline SRF7 & At3gl4350 & AY518292 \\
\hline SRF8 & At4g22130 & AY518293 \\
\hline
\end{tabular}

Methods). Conceptual translation indicates that the two SRF1 variants share the ECD and the TM but differ in their intracellular domains. Thus, SRF1 is likely to encode two proteins: a LRR-RLK (SRF1A) and a membrane-anchored LRR receptor-like protein (LRR-RLP) (SRF1B) that lacks most of the intracellular domain. Prominent examples of genes encoding membrane-anchored LRR-RLPs include CLAVATA2 (CLV2), TOO MANY MOUTHS (TMM) or $R P P 27$ from Arabidopsis and $C f-9$ from tomato [43-46].

\section{SRF I is characterised by a high degree of polymorphism between the Ler and Col accessions}

The $s u b$ phenotype in above-ground tissues is much less prominent in the Col background [29]. An initial genetic analysis indicated the existence of a genetic modifier, located on the second chromosome and linked to the ERECTA (ER) locus (D. C. and K.S., unpublished observations). SRF1 is located on chromosome 2 within a short distance to ER. Thus, we tested whether or not there is noteworthy polymorphism in the SRF1 sequence when comparing the Ler and Col accessions. We did observe an unusual amount of polymorphisms in SRF1 (Tables 3 and 4 , Figure 5) although subsequent studies indicated that SRF1 is not the modifier (unpublished results, see also below). We sequenced genomic DNA of the Ler SRF1 locus spanning nucleotides 8982429 to 8986460 (numbers as in Col) and we sequenced full-length cDNAs obtained from mRNA isolated from Ler and Col accessions (see Materials and Methods). Within the $3.986 \mathrm{~kb}$ of SRF1 genomic sequence covering the coding sequence we observed a total of $78 \mathrm{Ler} / \mathrm{Col}$ polymorphisms or about 20 polymorphisms per $1 \mathrm{~kb}$. This is in contrast to the average number of polymorphisms between two accessions which is about 4 polymorphisms per $1 \mathrm{~kb}$ genomic DNA across all sequence types and somewhat lower in coding regions [47].

Out of these 78 polymorphisms 68 correspond to simple nucleotide polymorphisms (SNPs) and 10 to small inser- tions/deletions (indels). The indels encompass 5 insertions (from 2 to $6 \mathrm{bp}$ ) and 5 deletions (from 1 to $6 \mathrm{bp}$ ). Eight indels are located in introns, and two deletions are found in the 3' UTR. Of the SNPs, 18 are located in introns, two are present in the 5' UTR, one is located in the 3' UTR, and 47 SNPs are present in exons. The other SRF genes do not exhibit similarly elevated levels of polymorphisms between Ler and Col (B. E., A. F. and K. S., unpublished observations; R. Clark and D. Weigel, pers. communication).

The polymorphisms are not equally distributed along SRF1. At the nucleotide level about $21 \%$ of the polymorphisms are located in the region encoding the ECD whereas $79 \%$ are found in the intracellular domain. At the predicted protein level, 23 of the 25 non-synonymous residue changes map to the intracellular domain (Figure 5, Table 4), with the JM featuring 10 amino acid alterations and the kinase domain 12 changes. This finding suggests that the polymorphisms affect, in particular, SRF1A. It is unclear if the polymorphisms influence protein function. Many of those nucleotide polymorphisms may do so as they alter the predicted protein sequence. Of the nucleotide polymorphisms located in exons, 26 result in amino acid changes of which at least six result in residues with different chemical and spatial properties. However, only one such alteration, a change from proline $(\mathrm{Col})$ to leucine (Ler) at position 600 in SRF1A and situated just between kinase subdomains VIa and VIb, affects a residue strictly conserved between SRF proteins (Figure 3B). The other polymorphisms reside at positions occupied by amino acids that are not conserved or only partially conserved among the SRF proteins.

\section{Functional analysis of SRF genes}

$S R F$ gene function was assayed by analysing the morphology of several independently isolated T-DNA insertion lines for each $S R F$ gene. In addition, we tested srf1 srf3, srf4 srf5, and srf6 srf7 double mutants (for a detailed descrip- 
SRF1

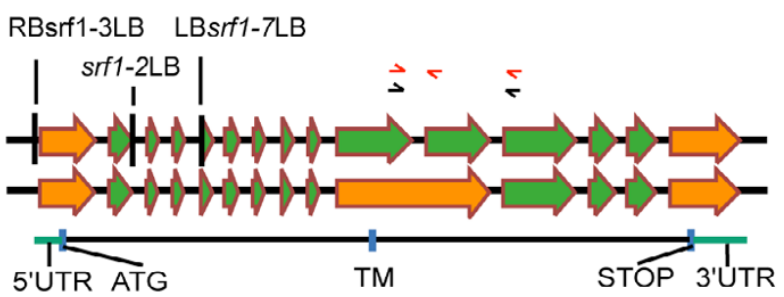

SRF2

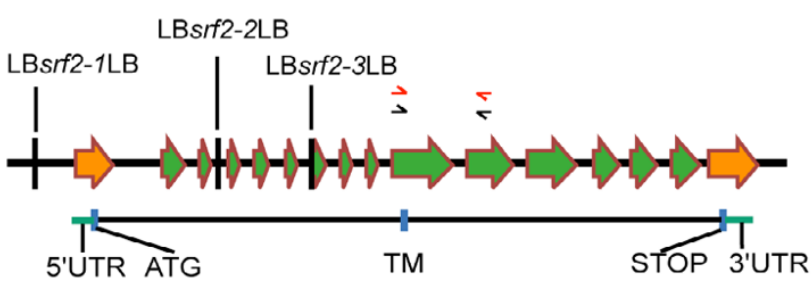

SRF3

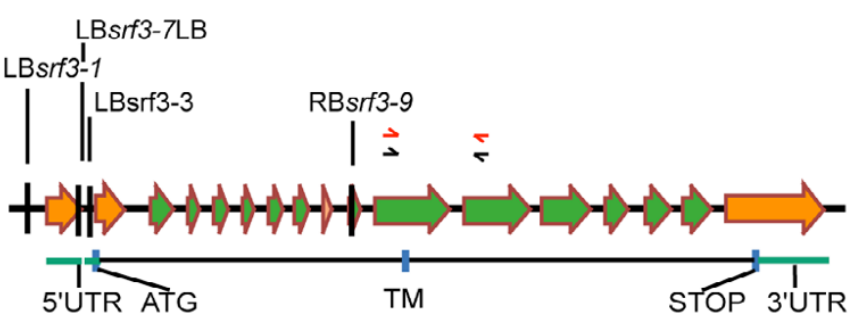

SRF4

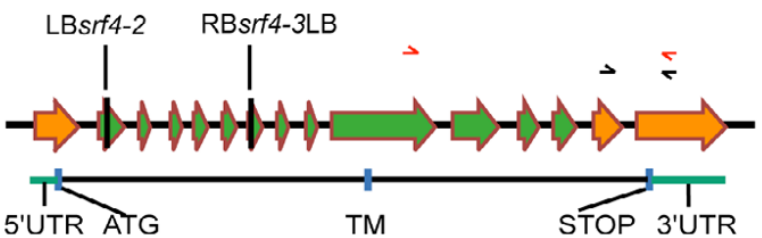

SRF5

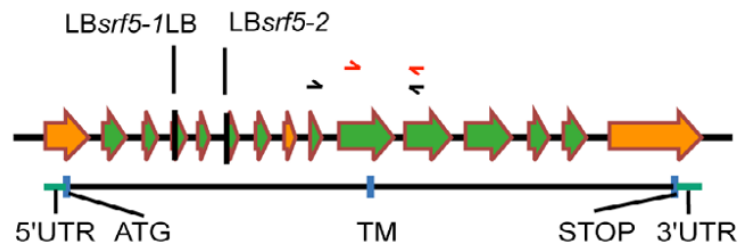

SRF6

LBsif6-4

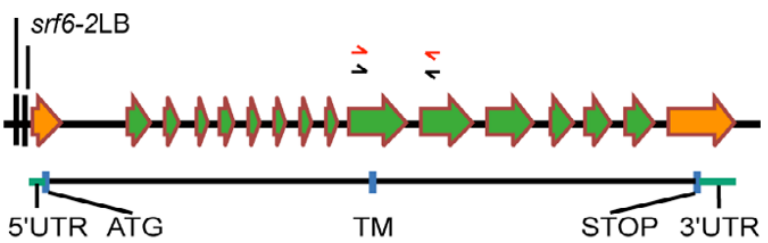

SRF7

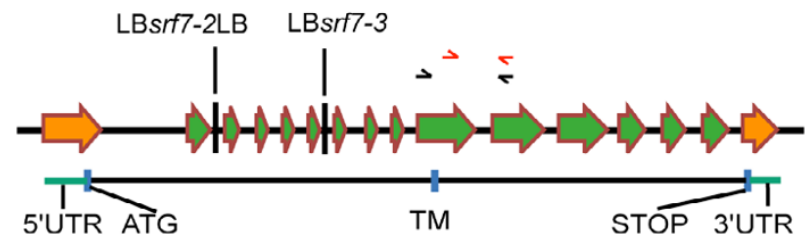

SRF8

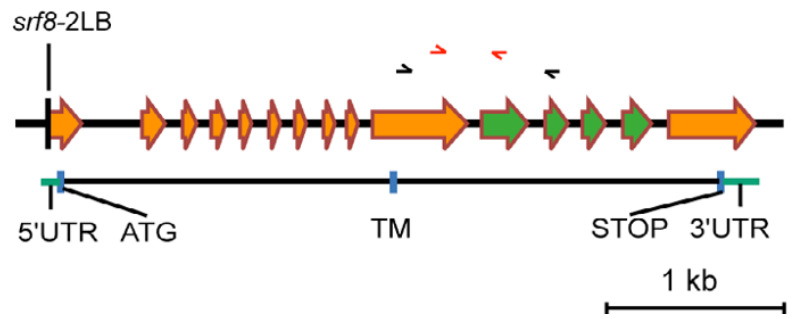

\section{Figure I}

Molecular organisation of SRFI-8. The large arrows indicate exons. Green arrows mark exons that had been correctly predicted while orange arrows highlight corrected exon annotation based on the cDNA and sequence analysis presented in this work. The insertion sites of the various T-DNAs are indicated. The small black arrows represent the primers used to investigate expression of the gene in the indicated homozygous srf T-DNA insertion mutants. The small red arrows highlight primers used to investigate differential splicing. Abbreviations: LB, left border of T-DNA; RB, right border of T-DNA; TM, transmembrane domain; UTR, untranslated region.

tion of insertion lines see Figure 1, Additional file 1, and Methods), thereby assaying the possible functional redundancy of these gene pairs. Mutant and wild-type plants were grown on soil in a greenhouse and scored in a systematic fashion for phenotypes at various developmental stages (see Methods).
Plants with altered SRF4 activity show a phenotype that indicates that SRF4 plays a role in the regulation of leaf size (Figure 6G, Table 5). We noticed that about $80 \%$ of homozygous mutant plants of two independent T-DNA insertion lines, srf4-2 and srf4-3, exhibited a reduction in leaf size. Leaf blade dimensions were measured using as 

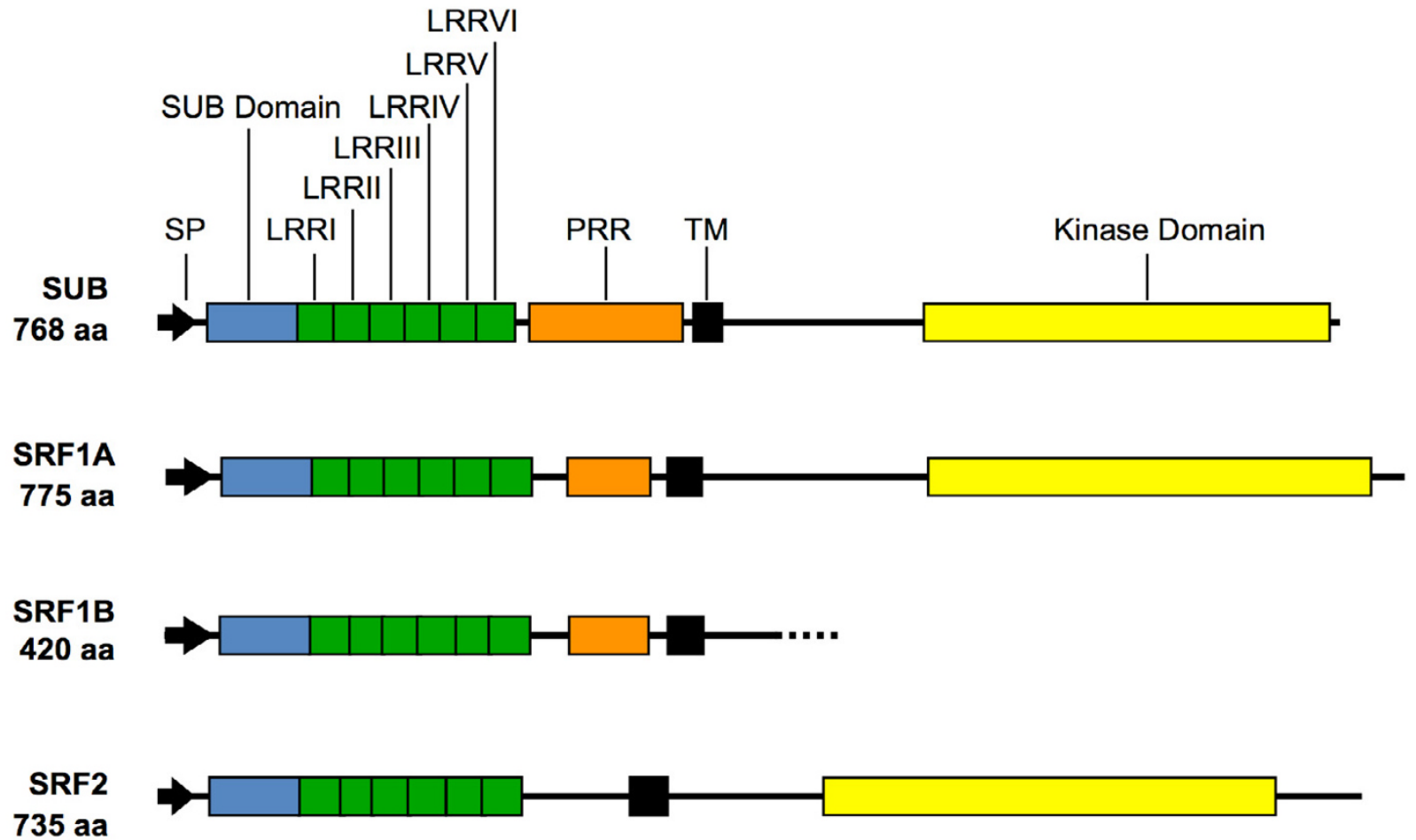

SRF3

776 aa

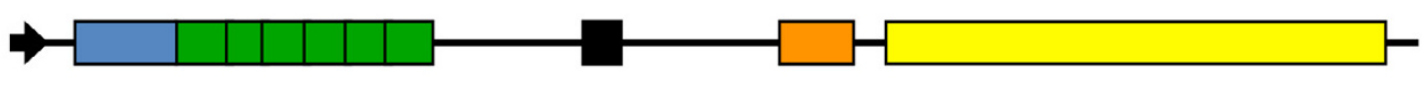

SRF4

687 aa
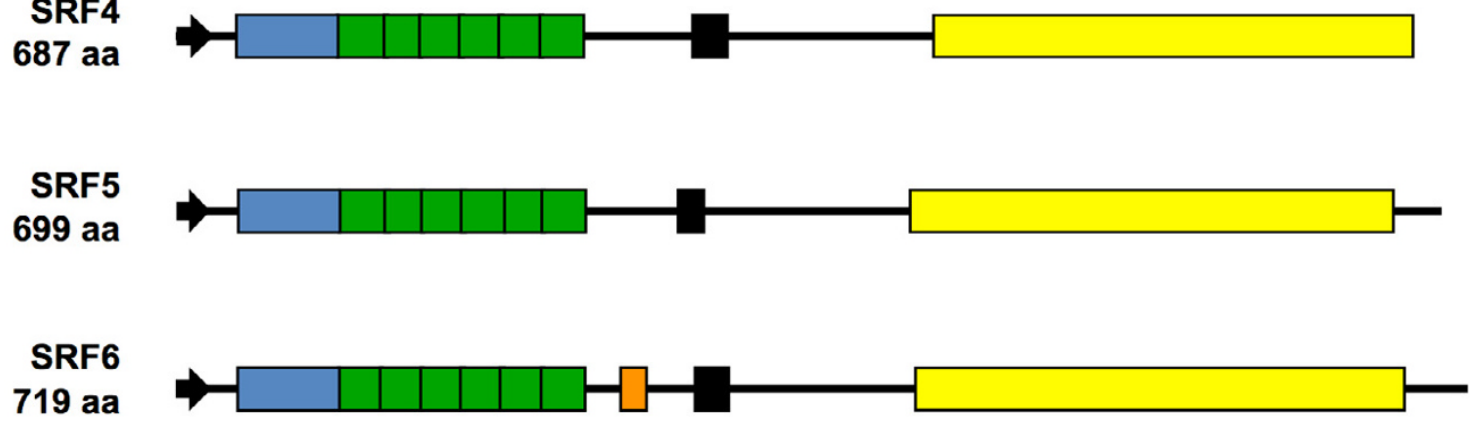

SRF7

717 aa

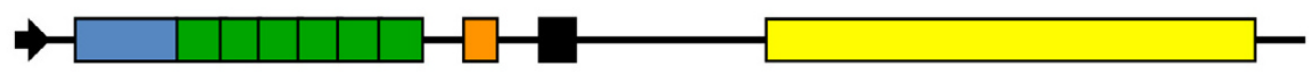

SRF8

703 aa

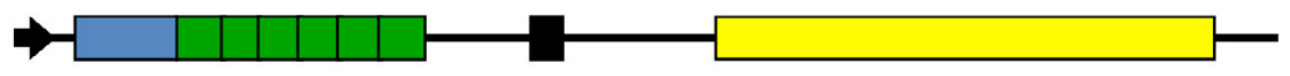

Figure 2

Domain organisation of SRF proteins. Abbreviations: LRR, leucine-rich repeat; PRR, proline-rich region; SP, signal peptide; TM, transmembrane domain. 
Table 2: Amino acid identities among SRF proteins

\begin{tabular}{lcccccccc}
\hline & SRF2 & SRF3 & SRF4 & SRF5 & SRF6 & SRF7 & SRF8 & SUB \\
\hline SRFI & \multirow{2}{*}{32.5} & 57.9 & 32.5 & 34.9 & 37.1 & 36.7 & 41.0 & 40.0 \\
SRF2 & & 32.8 & 34.4 & 34.9 & 36.0 & 34.8 & 34.8 & 29.6 \\
SRF3 & & & 34.1 & 35.2 & 38.7 & 38.4 & 39.7 & 42.6 \\
SRF4 & & & 55.6 & 43.6 & 44.5 & 40.8 & 32.5 \\
SRF5 & & & & 45.0 & 45.0 & 42.1 & 35.1 \\
SRF6 & & & & & 77.9 & 47.5 & 34.2 \\
SRF7 & & & & & & & & \\
SRF8 & & & & & & & & 34.2 \\
\end{tabular}

standard the fifth rosette leaves [48] taken from different 16-days-old plants grown simultaneously and under similar conditions. Both alleles showed an approximate 20\% reduction in the length and width of the leaf blade. This translates to a decrease of $40 \%$ in the surface area of the leaf blade. Interestingly, transgenic wild-type Col plants ectopically expressing SRF4 using the 35S promoter of cauliflower mosaic virus [49] exhibited leaves of increased size. We tested five transgenic lines with enlarged leaves and those lines exhibited elevated levels of transgene expression (not shown). Two independent homozygous 35S::SRF4 lines were characterized further (T3 generation, lines 3-12 and 1-5, respectively). We noted a $25-30 \%$ increase in length and width of the leaf blade, translating into a $40-50 \%$ increase in the surface area of the leaf blade. Interestingly, leaf shape appeared about normal in srf4 and 35S::SRF4 plants. This is also indicated by the constant length/width ratios of leaf blades across the two types of mutants and the wild type (Table 5).

Taken together these findings provide genetic evidence that SRF4 is a direct positive regulator of leaf size. The basis of the slightly reduced penetrance in the two srf4 mutants is unclear. The insertions in both srf4 alleles reside in exons encoding part of the extracellular domain of SRF4. In particular, srf4-2 is predicted to carry only a very short form of the ECD (Figure 1). It is therefore unlikely that residual SRF4 function in srf4-2 accounts for the reduction in penetrance. It is also unlikely that partial compensation of SRF4 function by its closest relative SRF5 explains the reduced penetrance of the leaf size phenotype in srf4 mutants. The analysed mutant alleles of SRF5, srf51 and srf5-2, apparently looked normal, transgenic 35S::SRF5 plants did not exhibit noticably bigger leaves, and srf4-2 srf5-1 double mutants essentially resembled srf4-2 single mutants (not shown). Thus, the results suggest that the reduced penetrance of the srf4 phenotype relates to other, as yet unknown factors.

Apart from srf4 mutants, all other T-DNA-induced mutants exhibited apparent wild-type morphology. We could also detect no obvious differences from wild type when light-grown mutant plants were tested for germina- tion behavior and root growth defects on $0.5 \times$ MS agar plates, supplemented with $1 \%$ sucrose. As previously reported, the sub phenotype is much more pronounced in the Ler background compared to Col [29]. As the T-DNA insertion lines are Col-derived, individual srf T-DNA alleles were crossed into a Ler background (see Methods). Again, apart from the defects in srf4 plants, we could detect no additional phenotypes/defects in srf mutants. The lack of phenotypes could be in part due to the fact that the T-DNA insertions in those lines only lead to an incomplete loss of SRF function. We could detect transcripts in all tested T-DNA lines when using primers (Figure 1) directed to a position located 3 ' to the T-DNA integration site (not shown). In the case of SRF1-5, however, at least one line had a T-DNA insertion situated in an exon encoding part of the ECD indicating that those insertions should severly impair protein function. The situation is less clear for the insertions in SRF6-8. The insertion sites in srf6-2 and srf6-4 are located within 50 base pairs 5' to the start of the SRFG coding region. The insertion site of srf8-2 resides in the 5' UTR. Therefore, the observed transcript levels could result in sufficient SRFG and SRF8 activity. The insertion sites in srf7-2 and srf7-3 are located in introns. In both lines correctly spliced mRNA molecules could be detected by RT-PCR using primers flanking the intron carring the insertion (Figure 1) (not shown) again leaving the possibility that sufficient SRF7 activity is present in those T-DNA insertion lines.

To gain further indications as to the function of individual $S R F$ genes transgenic plants were generated that ectopically express $S R F 1 A, S R F 1 B$ and $S R F 2-8$ cDNAs under the control of the $35 \mathrm{~S}$ promoter. Again Ler and Col wild-type backgrounds were used and transgenic plants were assayed for transgene expression (see Methods). No obvious phenotypes were detected in plants carrying $35 S:: S R F 1 B$ or $35 S:: S R F 6$ constructs. In contrast, $35 S:: S R F 2 / 3 / 5 / 7$ plants (Col), while otherwise normal in appearance, exhibited sterility (at least 5/50 transgenic plants; Figure 6). The 35S::SRF4 plants (Col) also showed sterility in addition to the leaf-size phenotype outlined above. Closer analysis of open flowers revealed all five different transgenic plants to carry mature anthers that in the 


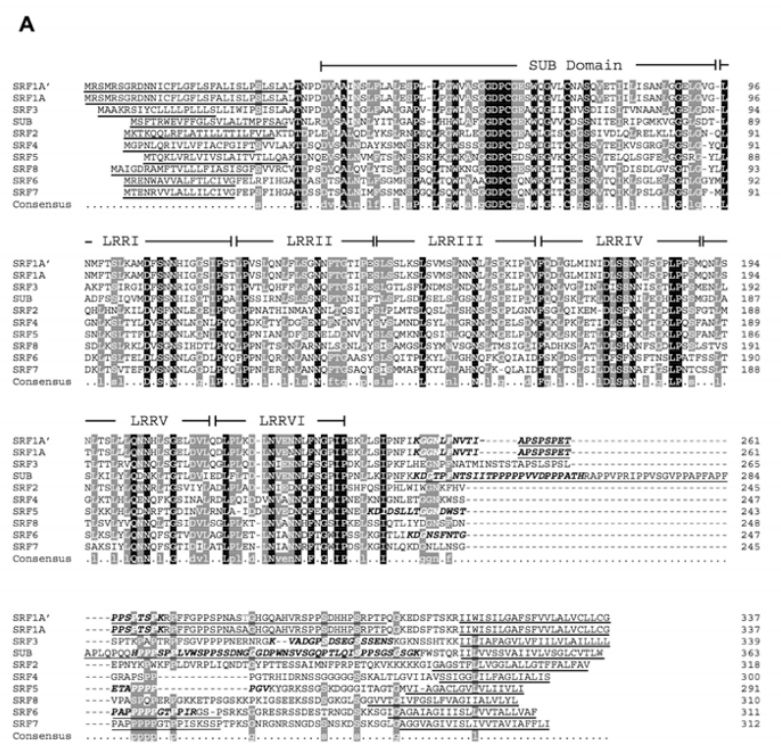

B
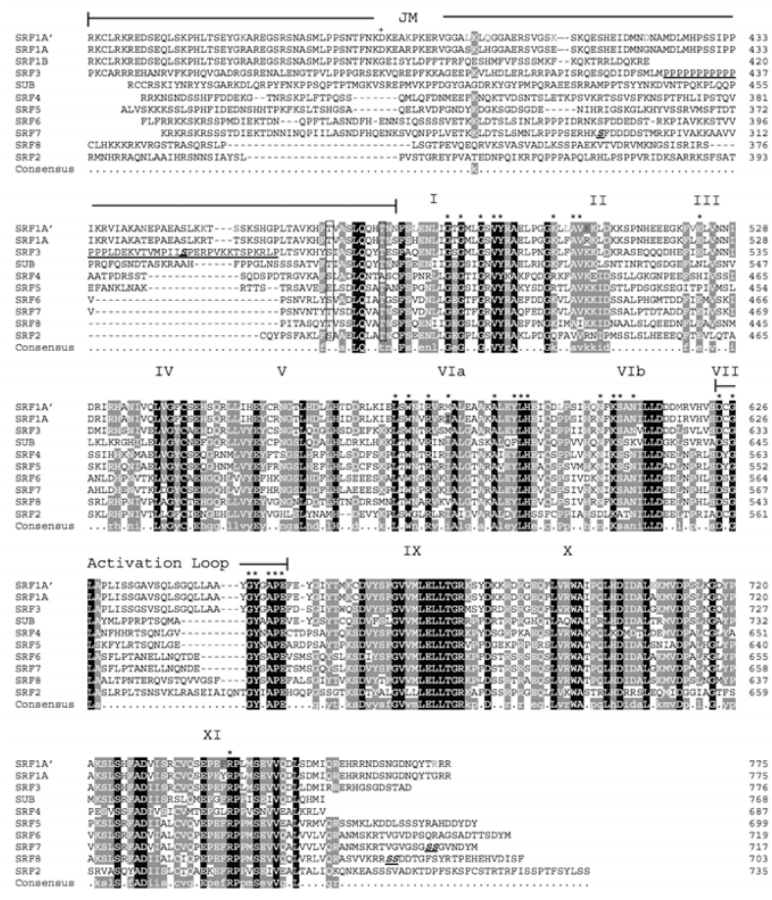

775
775
776
768
768
697
699
719
717
703
735

\section{Figure 3}

Protein sequence alignment of SRF proteins. SRFIA' represents the Ler version of SRFIA. All other sequences correspond to Col. Individual protein domains are indicated above the sequences. Full conservation across the alignment is marked by black columns, partial conservation by gray columns. Red color highlights a non-conservative residue exchange. Blue color marks a conservative or semi-conservative amino acid exchange. 3a) Alignment of predicted SRF amino acid sequences up to and including the transmembrane domain. Individual protein domains are indicated above the sequences. The predicted signal peptide sequences and the transmembrane domains are underlined with thick black lines. The proline-rich regions are underlined with thin black lines. Predicted PEST sequences are kept in italic. 3b) Alignment of predicted SRF amino acid sequences from juxtra-membrane domain up to and including the C-terminus. Asteriks highlight important kinase residues as revealed by standard kinase alignments [38]. SRFI: the cross in the juxtamembrane region marks the point of deviation of the SRFIA/B sequences. The proline-rich region of SRF3 is underlined with a thick black line. The 12 kinase subdomains are indicated. The in vivo phosphorylation sites of SRF3 (S. Peck, pers. communication), SRF7, and SRF8 are highlighted in italics and are underlined. 


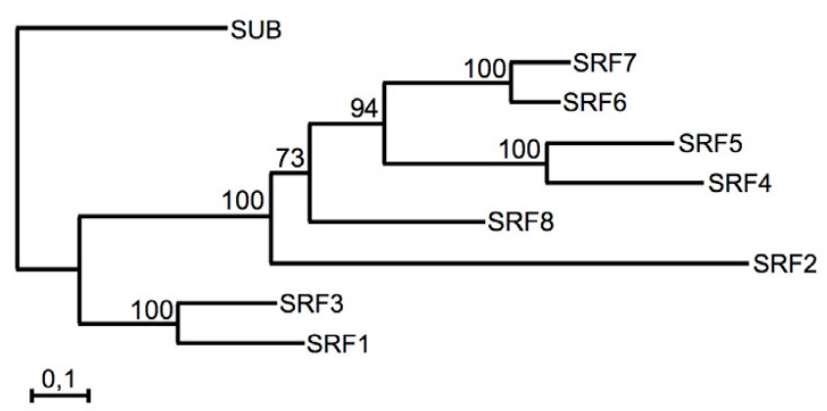

Figure 4

Phylogenetic tree of SRF family. A maximum likelihood tree obtained using as input the amino acid sequences of the combined SUB and kinase domains of SRF members. The branch support values are indicated.

most extreme cases failed to produce any visible pollen, while ovules appeared normal. Pollinating sterile plants with wild-type pollen resulted in normal seed production indicating that such plants were male-sterile (data not shown). In the case of different 35S::SRF4, 35S::SRF5, and 35S::SRF7 lines the sterility correlated with increased transgene expression while for 35S::SRF2 and 35S::SRF3 lines no strict correlation could be detected (not shown). In the Ler background only ectopic expression of SRF3 and SRF4 led to male sterility, indicating the importance of genetic background in these experiments.

The situation for 35S::SRF1A and 35S::SRF8 plants was more complex. We noticed that the majority of resistant T1 seedlings failed to generate rosette leaves. The seedlings featured cotyledons, stayed green for several weeks and then died (B.E., data not shown). This finding was observed in Ler and Col backgrounds and indicates that ectopic expression of SRF1A and SRF8 may lead to seedling lethality. Conversely, viable transgenic 35S::SRF1A and 35S::SRF8 plants, that also expressed the transgene, were isolated. These plants showed no apparent mutant phenotype. The basis for the discrepancy is presently not understood. Unfortunately, due to the apparently normal anther development and fertility in the different srf $\mathrm{T}$ -
DNA insertion lines it is presently difficult to decide whether or not the sterility exhibited by some of the $35 S:: S R F$ transgenic plants relates to the wild-type function of the corresponding gene. A similar restriction applies to the seedling lethality.

To test if different SRF genes could substitute for SUB function we generated separate sub-1 plant lines, where each line was transgenic for one of the individual nine $35 S:: S R F$ constructs. While at least 50 transgenic sub-1 35S::SRF T1 plants were screened per construct, no rescue of the $s u b-1$ phenotype was observed. Seedling lethality, as described above, for sub-1 35S::SRF1A and sub-1 35S::SRF8 plants was again present, however, again several viable sub-1 35S::SRF1A and sub-1 35S::SRF8 plants expressing the transgene were isolated (see Methods). These plants showed a sub-1 phenotype. As the sub-1 phenotype disappears in sub-1 35S::SUB plants [29] our results suggest that $S R F 1-8$ cannot functionally replace $S U B$ in this genetic assay.

\section{Global gene expression analysis}

RT-PCR analysis (Figure 7) indicated that most SRF transcripts are present in a broad pattern. SRF5 expression may be the exception, as its expression levels are not easily detectable by RT-PCR, in siliques, stems, roots and seedlings. To analyse the expression profiles of SRF genes at a global scale, including many developmental stages and experimental conditions, we made use of a large set of GeneChip expression data publicly available at The Nottingham Arabidopsis Stock Centre (NASC) [50,51] (see Methods). The data set used comprises 1784 Affymetrix chips (ATH1 platform) and more than 100 experiments covering a wide range of tissues, developmental stages and environmental conditions. Probe sets of the ATH1 GeneChip were realigned to the Arabidopsis whole genome sequence to exclude non-unique probes. All SRF genes including $S U B$ are described by specific probe sets (see Methods). The experimental set up did not allow a discrimination between SRF1A and SRF1B. By interrogating this dataset we targeted two objectives: to assay possible functional redundancy between SRF genes and to formulate hypotheses regarding the function of individual $S R F$ genes.

Table 3: Number of nucleotide polymorphisms in SRFIA (Col/Ler)

\begin{tabular}{lccccc}
\hline Polymorphism & Exons & Introns & 5'UTR & 3 'UTR & Total \\
\hline Insertion & - & 5 & - & - & 5 \\
Deletion & - & 3 & - & 2 & 5 \\
SNP & 47 & 18 & 2 & 38 & 78 \\
\hline Total & 47 & 26 & 2 & 3 \\
\hline
\end{tabular}

$\mathrm{Ka} / \mathrm{Ks}=1.23$ 
Table 4: Location of single nucleotide polymorphisms in various SRF IA domains. Abbreviations: JM, juxtamembrane domain; LRR, leucine-rich repeat; PRR, proline-rich region; SP, signal peptide.

\begin{tabular}{lccccccc}
\hline Polymorphism & SP & SUB Domain & LRR & PRR & JM & Kinase & C-Terminus \\
\hline Synonymous & I & 2 & 3 & I & - & 13 & - \\
Non-synonymous & - & - & 1 & 1 & II* & 12 & I \\
\hline Total & I & 2 & 4 & 2 & II & 25 & I \\
\hline
\end{tabular}

*Two of SNPs are located in the first and third codon position of a triplet

$\mathrm{Ka} / \mathrm{Ks}=0.25$ (extracellular)

$\mathrm{Ka} / \mathrm{Ks}=1.84$ (intracellular)

Abbreviations: JM, juxtamembrane domain; LRR, leucine-rich repeat; PRR, proline-rich region; SP, signal peptide.

\section{Correlation analysis of SRF transcript levels}

Is there redundancy between $S R F$ genes, such that an active $S R F$ gene (or several $S R F$ genes) could functionally replace the mutated $S R F$ gene? If so, one expects at least some co-expression of the redundant genes. Therefore, we performed a global correlation analysis of SRF transcript levels. Pearson correlation coefficients were determined for each SRF pair (Table 6). To compare the SRF correlations against random expectation, we computed allagainst-all gene pairs correlations of all genes present on the ATH1 chip (excluding self-correlations) to derive background expression similarities. Correlations were calculated as (metric) Pearson correlation coefficients. Mean and median of background distribution are $\mathrm{r}_{\text {Mean }}=0.08$ and $r_{\text {Median }}=0.05$ and the 80\%-, 95\%- and 99\%-quantiles are $0.51,0.71$ and 0.92 , respectively. For all SRF pairs, global correlations are considerably below the $0.95 \%$-quantile and, except for SRF4 and SRF5, even below the 80\%quantile (see Table 6). Thus, with the possible exception of SRF4/SRF5, global expression correlations provide no support for strong redundancies between $S R F$ genes but indicate instead at least partially specific expression patterns.

\section{Expression profiling of SRF genes}

One way to gain further leads into possible gene function is to ask whether or not a particular gene is up- or downregulated at certain developmental stages or under certain experimental conditions. To investigate expression of $S R F$ genes in detail, $S R F$ expression levels were analysed for each experiment in the ATH1 GeneChip dataset. Replicates were summarized by their mean. Measurements were scaled such that expression levels for each chip had a mean of 0.0 and a variance of 1.0. Expression profiles for the SRF genes are shown in Figure 8. SRF gene expression is present over a wide range of experiments and most of them show, at least for particular experiments, specific profiles. This corroborates the analysis of global expression correlations and conclusions about partly independent functionalities of SRF genes.
SUB generally has expression levels below average. It displays accented expression levels in two large developmental series. In both series, shoot apices at the bolting stage have elevated $S U B$ levels. In contrast, $S R F 1$ profile exhibits several distinct gene inductions or repressions in experiments investigating programmed cell death, tumor development, control of lignification and pectin biosynthesis. SRF2 shows an overall low and unspecific broad expression. As expected from their global correlations, SRF4 and SRF5 show the highest similarity in their profiles, with SRF5 having remarkably lower expression levels. Both genes appear to exhibit highly pronounced expression in mature pollen. It is possible, however, that the seemingly high levels of pollen expression in the GeneChip data set represents an artefact originating from the normalisation procedure as only $26 \%$ of the genes present on the ATH1 chip were detected in pollen samples while about $55 \%$ to $67 \%$ of the genes were detected in samples from most other tissues [51,52]. In this context it is interesting to note that srf4 mutants show altered leaf development but no apparent defect in pollen development or fertility. In addition, srf5 single mutants, and srf4 srf5 double mutants, show apparently normal pollen and are fertile plants. We could not confirm a notably strong expression of SRF4 and SRF5 in pollen using in situ hybridisation experiments as in our hands pollen regularly show increased background signals in such experiments ( $\mathrm{K}$. Pfister and K. Schneitz, unpublished observations). Although we did not perform quantitative experiments, the results from our RT-PCR analysis may indicate, however, that expression of both genes is perhaps more readily detected in developing flowers in comparison with many other tissues (Figure 7).

In contrast to the previous genes, expression profiles of SRF3, SRF6, SRF7, and SRF8 exhibit above average or high expression levels over a broad range of experiments. For these genes, we therefore describe only the most salient experiments, i.e. with the highest expression levels (arrows in Figure 8, NASC codes are given in the figure legend). The strongest expression levels of SRF3 are concord- 
A

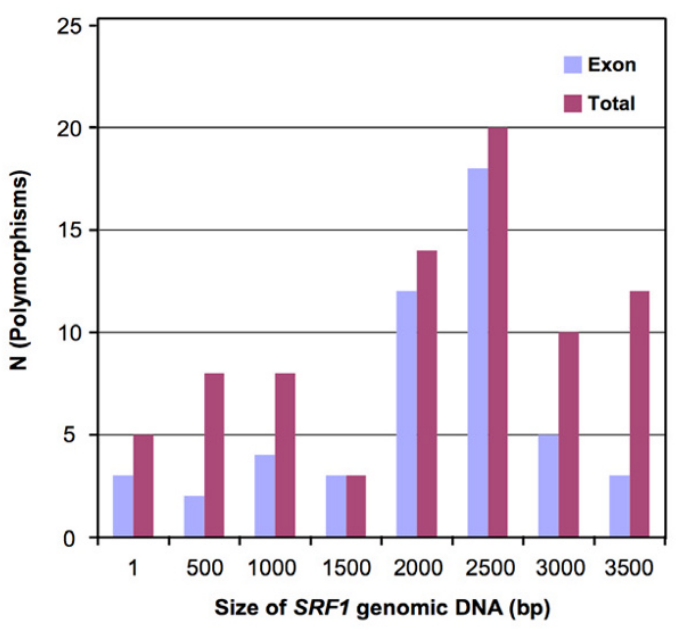

B

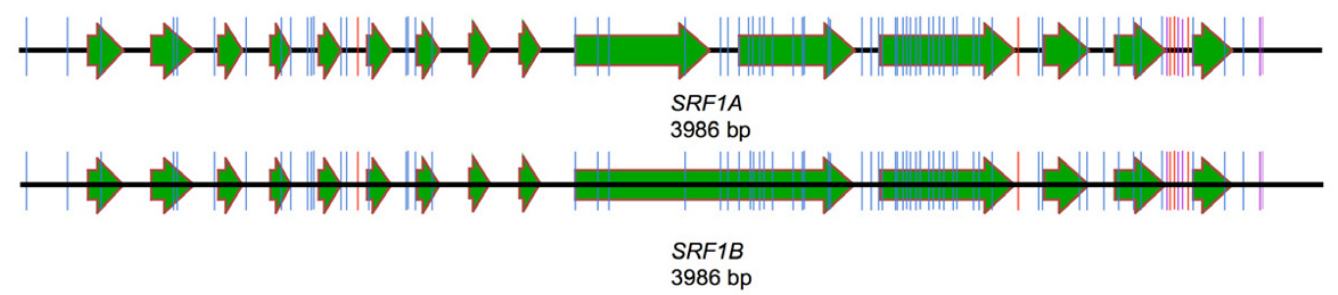

C

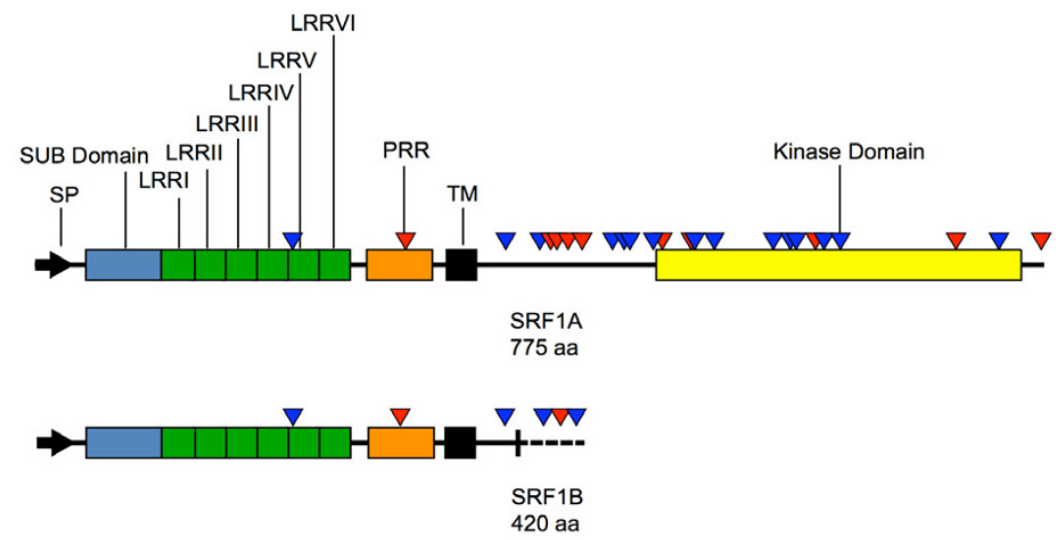

\section{Figure 5}

The SRFI Ler/Col polymorphisms. 5a) Frequency distribution of polymorphisms relative to the position within the SRFI locus. 5b) Graphic representation of the location of the polymorphisms within SRFI. Large arrows indicate exons. Blue color denotes a single nucleotide polymorphism, red color marks an insertion and purple color highlights a deletion. 5c) Graphic representation of the location of the polymorphisms within the putative SRFI proteins. The different C-terminus of SRFIB is marked by a vertical bar plus a dashed line. Polymorphisms are indicated by triangles. Red color highlights a non-conservative change, blue color a conservative or semi-conservative alteration. 

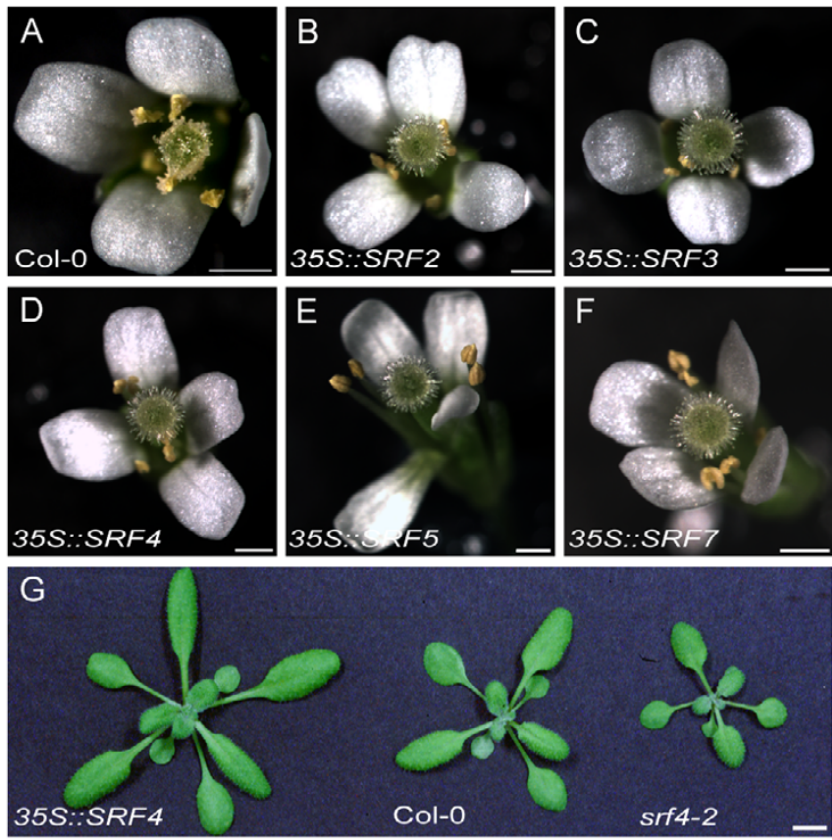

Figure 6

Phenotypic effects of altering SRF expression. 6a) An open wild-type flower. 6b-f) Flowers of same age as in 6a. Note the absence of mature pollen. $6 \mathrm{~g}$ ) Leaves of plants with altered SRF4 activity. The 35S:::SRF4 (line I-5), Col, and srf4-3 plants are indicated. Leaves are enlarged and reduced,

respectively. Note the regular leaf shapes. Scale bars: $0.5 \mathrm{~mm}$

ant to those of $S R F 1$, i.e. in experiments investigating programmed cell death, pectin biosynthesis, control of lignification and tumor development. In contrast to SRF1, however, SRF3 shows mid-level expressions in many other experiments. SRF6 was strongly induced in plants exposed for a prolonged time $(3 \mathrm{~h})$ to heat stress. Considerably elevated expression levels for SRFG were also observable for several light treatments, brassinosteroid treatments and pectin biosynthesis. Furthermore, strong inductions of SRFG were present in experiments analyzing expression in the Atrbohc/rhd2 mutant [53] and infections with fungi inducing arbuscular mycorrhiza symbiosis. As observed for SRF6, both SRF7 and SRF8 showed prominent expression in experiments analyzing effects on transcription for sulfate limitations and for the rhd2 mutant in Arabidopsis. In addition, the expression profile of SRF7 showed elevated levels in experiments involving various brassinosteroid treatments.

In summary, although expression profiles showed overlapping domains between various $S R F$ genes, an experiment-wide analysis of expressions corroborates our previous conclusions. That is, genetic redundancy, in the sense that at least some SRF genes are functionally interchangeable, is likely not a major cause for the lack of phenotypes in srf mutants.

\section{Enrichment of functional categories}

Previous reports have shown that co-expressed genes have an increased likelihood to be involved in a common biological process [51,54-56]. Coexpression information can therefore be used to transfer knowledge from annotated genes to genes of unknown function. We extended our expression correlation analysis to compare individual SRF expression levels with the expression levels of all Arabidopsis genes included on the ATH1 chip. Gene ontology (GO) annotations for Arabidopsis genes (GO slim) were obtained from TAIR $[37,57]$. From the all-against-all matrix of Pearson correlations, we selected the top 100 $(0.5 \%)$ correlated genes for each SRF gene. Overrepresentation of particular functional categories within each of these gene sets were tested by binomial probability. P-values were Bonferroni-corrected for multiple hypothesis testing. Corrected $\mathrm{p}$-values of $\mathrm{p} \leq 0.05$ were considered significant. Table 7 lists the detected functional categories for the different $S R F$ genes.

Curiously, our analysis detected only for SRF4, but not for $S R F 5$, a statistically significant enrichment for several functional categories. This result is somewhat surprising as both genes have a similar expression profile. Both profiles mainly differ in expression levels corresponding to their expression in mature pollen tissue while for most other experiments, both genes show basal or background

Table 5: Blade size of fifth rosette leaves in 16 day old plants

\begin{tabular}{ccccccc}
\hline Genotype & Length & Width & Leaf Index & Perimeter & Area & $\mathrm{n}$ \\
\hline Col-0 & $11.5 \pm 1.8$ & $6.8 \pm 1.0$ & 1.691 & $32.5 \pm 5.5$ & $63.5 \pm 19.2$ & 27 \\
35S::SRF4:myc.A & $13.9 \pm 1.9$ & $8.2 \pm 1.0$ & 1.695 & $38.0 \pm 4.8$ & $87.4 \pm 23.1$ & 25 \\
35S::SRF4:myc.B & $14.5 \pm 1.4$ & $8.8 \pm 0.8$ & 1.648 & $39.8 \pm 3.8$ & $95.3 \pm 15.8$ & 24 \\
srf4-2 & $9.2 \pm 1.4$ & $5.5 \pm 0.8$ & 1.673 & $25.0 \pm 4.0$ & $39.1 \pm 11.1$ & 13 \\
sif4-3 & $8.6 \pm 1.7$ & $5.4 \pm 1.0$ & 1.593 & $24.8 \pm 4.5$ & $38.9 \pm 12.8$ & 22 \\
\hline
\end{tabular}

Values are in $\mathrm{mm}$ except for the area column $\left(\mathrm{mm}^{2}\right)$. The mean $\pm \mathrm{SD}$ is shown. The mean values of all measurements between srf4 mutants, 35S:::SRF4 transgenic plants and wild type are statistically significant $(P<0.001$, Student's t-test). 35S::SRF4:myc.A and 35S::SRF4:myc.B correspond to transgenic lines 3-12 and I-5, respectively. aLength/width ratio of leaf blade. 
expression levels. The relatively small number of pronounced or informative expression peaks for this gene pair could influence our statistical test due to many small fluctuations from noise or background expression. Therefore, in our current analysis, it is not clear whether differences between SRF4 and SRF5 truly reflect different biological roles or may be due to an insufficient resolution/power of our approach. However, we were able to detect significant enrichments for GO annotations within their correlated genes for SRF3, SRF4, and SRF6-8. As expected, GO terms describing kinase signaling pathways were overrepresented in several gene sets. The set of SRF3 was enriched in Golgi-associated processes and the set of SRF4 in processes regulating pectinesterase activity. SRFG is potentially acting in pathways responding to fungal infections. SRF7 shows a strong association with proteins involved in the organization and biogenesis of the cell wall while SRF8 may act in sterol biosynthesis.

\section{Discussion \\ Differential splicing at the SRF I locus}

We found that differential splicing of the SRF1 transcript potentially leads to two types of proteins: a LRR-RLK (SRF1A) and a membrane-anchored LRR-RLP (SRF1B). Genes encoding putative RLPs represent a large family in plants $[8,58]$. As a rule, RLKs and RLPs are encoded by separate genes in plants $[8,58]$. Thus, $S R F 1$ is unusual as the RLK and RLP versions of SRF1 appear to be generated by differential splicing. In this respect, however, it resembles for example the Brassica gene encoding S-locus receptor kinase (SRK) from the $S_{3}$ and $S_{9}$ haplotypes $[59,60]$. Differential splicing of $S R K$ in those haplotypes results in multiple transcrips, one of which encodes the SRK while another encodes a soluble protein, carrying the ECD but not the TM or intracellular domain (eSRK).

The function of most plant RLPs is unknown $[8,58]$. To date, RLPs are known to affect processes as diverse as meristem regulation, stomata development, self-incompatibility, or pathogen resistance [43-46,61-63]. Interestingly, RLPs such as Xa21D, CLV2, TMM, or the S-locus glycoprotein (SLG) of Brassica, may affect the same process regulated by a RLK with a related ECD. For example, the LRRRLK Xa21 and the extracellular LRR-RLP Xa21D confer the same resistance spectrum to Xanthomonas oryzae pv oryzae, albeit with different strengths [63-65]. Genetic and biochemical evidence indicates that the membrane-anchored LRR-RLP CLV2 acts in the same pathway than the LRRRLK CLV1 and that CLV2 and CLV1 form a complex $[43,66,67]$. In addition, there is genetic evidence that the membrane-anchored LRR-RLP TMM functions in the stomatal patterning process regulated by members of the ERECTA family of LRR-RLKs [26]. The Brassica self-incompatibility protein SLG occurs in different forms but is generally an extracellular protein with an S-domain highly homologous to the S-domain of SRK $[68,69]$. The exact function of SLG is still under debate $[68,69]$, however, there is evidence that in certain S-haplotypes SLG is part of a protein complex that includes SRK $[70,71]$. SLG enhances the self-incompatibility response in some $S$ haplotypes [72] and one function of SLG may reside in the stabilisation of SRK [73].

Whether or not SRF1A and SRF1B act in the same protein complex remains to be investigated. In this context it is interesting to note that SRF1A may differ from SRF1B in its biological activity as indicated by the presence of seedling lethality exhibited by some 35S::SRF1A plants, but not by $35 S:: S R F 1 B$ plants. Thus, differential splicing at the SRF1 locus may result in two SRF1 protein variants with distinct biochemical and possibly biological properties.

\section{SRF I exhibits high levels of Ler/Col polymorphisms}

A high number of polymorphisms were found when comparing SRF1 sequences between Col and Ler. Several Arabidopsis genes exhibit such elevated levels of polymorphisms. These include a large number of nucleotide-binding site plus leucine-rich repeat (NBS-LRR) genes, a domain organisation characteristic of many plant resistance $(R)$ genes [74-76], but also developmental regulators such as APETALA 3 (AP3), CAULIFLOWER (CAL) $[77,78]$, or CLV2 [43].

Most $R$ genes of the NBS-LRR class are organised in single units, clusters, and superclusters [76]. $R$ genes are involved in gene-for-gene interactions $[79,80]$. The presence of a specific allelic variant of an $R$ gene and a corresponding specific avirulence allele from the pathogen in both host and pathogen results in disease resistance. In the case of NBS-LRR-class R proteins the C-terminal LRRs are likely to be important for the specificity of $\mathrm{R}$ protein and avirulence protein interaction. In accordance with this view, such $R$ genes are characterized by high variability in the LRR-coding regions and population genetic analysis indicates that balanced selection acts to maintain resistant and susceptible alleles [81-86]. Interestingly, the CLV2 polymorphisms affect mainly the N-terminal LRRs in the ECD [43], which are likely to be involved in ligand binding.

Whether or not $S R F 1$ is under balancing selection remains to be seen. The large number of SRF1 polymorphisms is evident in a Ler/Col comparison. SRF1 does not appear to diverge much from Col in several other accessions ( $R$. Clark and D. Weigel, pers. communication). In addition, SRF1 is not situated in a generally polymorphic genomic region although the neighbouring locus At2g20840 also exhibits elevated levels of Ler/Col polymorphisms (R. Clark and D. Weigel, pers. communication). At2g20840 encodes a protein annotated as a secretory carrier mem- 


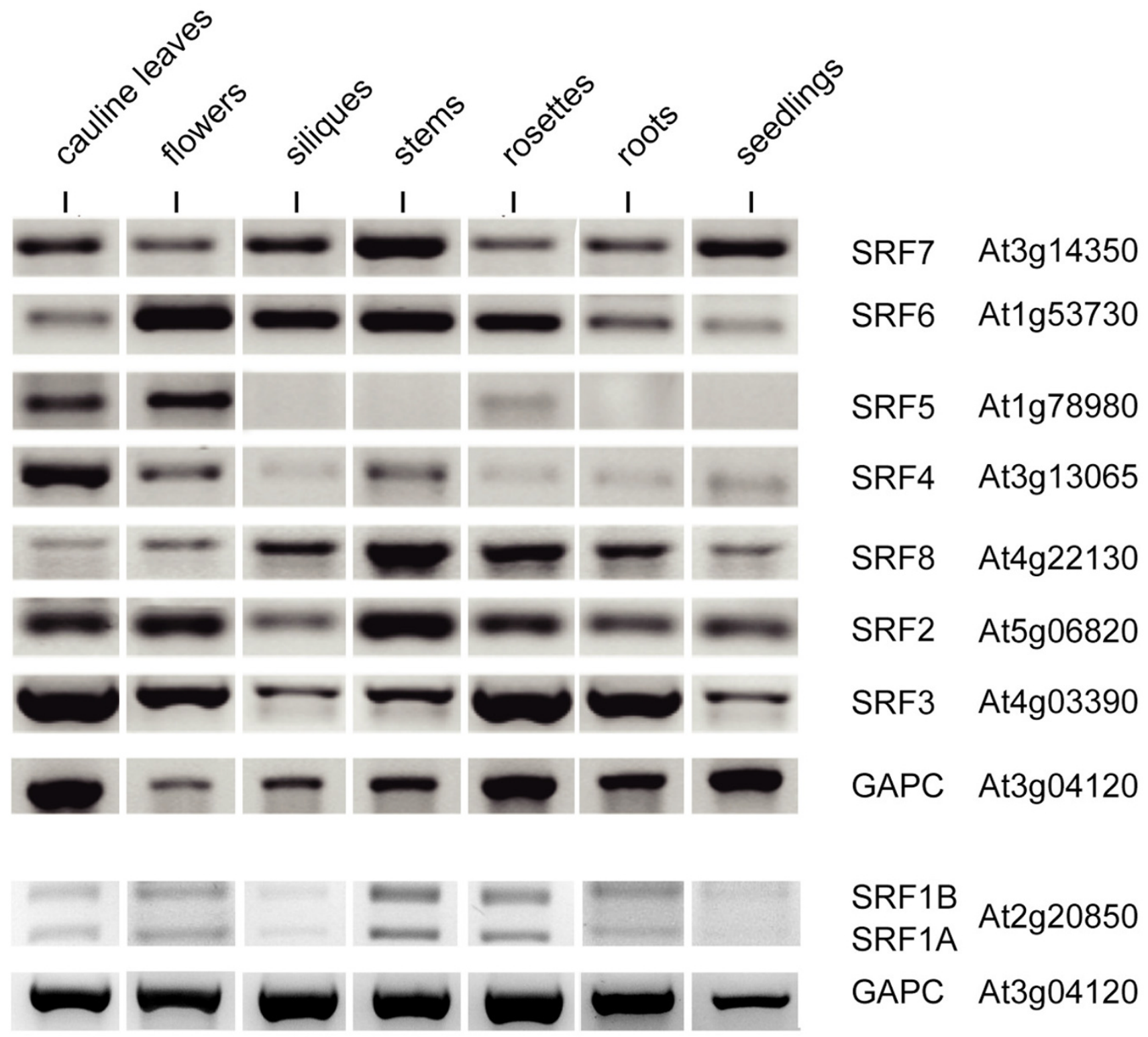

Figure 7

RT-PCR-based expression profiles of SRFI-8. The SRF genes are detectable in a broad fasion, albeit at varying levels. Note the two different SRFI-related bands. The SRFI-related experiments were based on separate mRNA isolates. Therefore, a second GAPC control was included.

brane protein (SCAMP) possibly acting in endocytosis. It should also be noted that the allele is rare and if under balancing selection, is maintained at very low frequency. The $\mathrm{K}_{\mathrm{a}} / \mathrm{K}_{\mathrm{s}}$ ratio, the ratio of nonsynonymous over synonymous amino acid substitutions, may point to an influence of balancing selection. A ratio exceeding unity is compatible with balanced selection. Taking the entire SRF1 protein into account, the $\mathrm{K}_{\mathrm{a}} / \mathrm{K}_{\mathrm{s}}$ ratio is 1.25 (25 non- synonymous/20 synonymous amino acid substitutions). In addition, the asynonymous changes are mainly concentrated in a particular region of SRF1. Considering the ECD and the intracellular domain (JM/CD/C-terminus) separately, one observes values of 0.29 and 1.85 , respectively (Table 4). Thus, and in contrast to CLV2, the SRF1 polymorphisms mainly affect the intracellular domains of the predicted SRF1 proteins. 
Table 6: Pairwise Pearson correlation coefficients for the expression correlation analysis of SRF genes

\begin{tabular}{lllllllll}
\hline & SRF2 & SRF3 & SRF4 & SRF5 & SRF6 & SRF7 & SRF8 & SUB \\
\hline SRFI & 0.156 & 0.282 & 0.057 & 0.163 & -0.06 & -0.22 & -0.04 & 0.175 \\
SRF2 & & -0.19 & 0.319 & 0.522 & -0.22 & -0.21 & -0.21 & 0.227 \\
SRF3 & & -0.16 & -0.29 & 0.413 & 0.215 & 0.311 & 0.178 \\
SRF4 & & & 0.655 & -0.17 & -0.16 & -0.15 & 0.046 \\
SRF5 & & & & -0.23 & -0.32 & -0.19 & -0.01 \\
SRF6 & & & & & 0.428 & 0.487 & 0.037 \\
SRF7 & & & & & & & 0.471 & 0.076 \\
SRF8 & & & & & & & & \\
\hline
\end{tabular}

All pairwise correlations are below the $95 \%$-quantile of the background correlation distribution $(0.7 \mathrm{I})$.

\section{SRF4 is required for the control of leaf size}

The genetic results presented in this paper suggest that SRF4 is a direct positive regulator of leaf size but not leaf shape. Organ size depends on the coordination of cell proliferation and cell size [87-90]. It is poorly understood how this coordination is regulated and only few genes are known that when overexpressed cause altered organ size but do not interfere with differentiation. Such genes are postulated to be involved in the control of an organ-size checkpoint $[89,91]$. One key element in organ size control is the positive regulation of the duration of cell proliferation during organ development (meristematic competence of organ cells). The current evidence suggests that auxin, in an AUXIN-RESISTANT1-dependent fashion, upregulates transcription of the ARGOS gene encoding a protein of unknown biochemical function [92]. Plants that exhibit reduced or ectopic expression of ARGOS show reduced or enlarged aerial organs, respectively. ARGOS mediates its effects through AINTEGUMENTA (ANT) [92]. ANT encodes a member of the AP2/EREBP class of transcription factors [93-95]. Plants with altered ARGOS or ANT activities share many similarities and ARGOS acts as a positive regulator of ANT expression [92]. Plants with reduced ANT activity show a number of defects including a variably reduced floral organ number, narrow floral organs and reduced ovule primordium and integument outgrowth $[28,93,94,96,97]$. In contrast, ectopic expression of ANT leads to leaves and floral organs, including ovules, with increased size and normal shape [91,98]. ANT largely influences the final number of cells in an organ and in turn mediates its function in part through cell cycle regulators such as $C \gamma c D 3 ; 1[91,99]$.

With respect to leaves recent evidence suggests that distinct processes regulate cell proliferation and cell expansion along the longitudinal (proximal-distal) and lateral (transverse) axes, respectively [100]. In addition, the plate meristem of leaf primordia sustains two-dimensional growth of leaf blades as lamina cells divide in random directions [101]. Two genes, ANGUSTUFOLIA3 (AN3) and GROWTH-REGULATING FACTOR5 (AtGRF5), are implicated as positive regulators of cell proliferation in the plate meristem [102]. AtGRF5 encodes a putative transcription factor [103]. AN3 is identical to GRF-INTERACTING FACTOR1 (AtGIF1) [104]. AN3/AtGIF1 encodes a homolog of the animal transcriptional coactivator SYT and AN3/ATGIF1 can dimerise with ATGRF5 in yeast [102]. Plants defective in AN3/AtGIF1 function exhibit a reduction in leaf cells due to decreasing plate meristem activity. Loss-of-function mutations in AtGRF5 lead to similar, though milder effects. By contrast, ectopic expression of AN3/AtGIF1 or AtGRF5 results in normally shaped but larger leaves. The combined genetic and molecular data support the notion that AN3/ATGIF1 and ATGRF5 act together to promote plate meristem activity and thus leaf size [102].

The positive regulation of cell expansion is also important for leaf size and involves ARGOS-LIKE (ARL), a gene related to ARGOS [105]. At the organ level manipulating the levels and/or duration of $A R L$ activity results in similar effects on organ size than related alterations in ARGOS activity. Interestingly, $A R L$ is required for general cell expansion, as opposed to polar cell expansion/elongation, during organ growth. ARL appears to mediate BRrelated signaling in general cell expansion. Thus, although $A R G O S$ and ARL are structurally related genes that affect leaf size, they do affect different cellular processes during organogenesis. Other promoters of cell expansion and leaf size include AtGRF1, AtGRF2, and AtGRF3, homologs of AtGRF5 [103]. Single or various double-mutant combinations of single mutant alleles showed either no or only small defects in leaf growth. A grf1 grf2 grf3 triple null mutant, however, exhibited an approximate $32 \%$ reduction of the surface area of third leaves. 35S::AtGRF1 or 35S::AtGRF2 plants exhibited variably increased leaf size. A cellular analysis of the phenotypes indicated that the leaf-size defects are due to corresponding alterations in cell size [103]. In addition, several so-called extra-small sisters $(x s)$ mutants with a defect in cell expansion, leading to reduced leaf size but normal leaf shape, have recently been isolated [106]. 

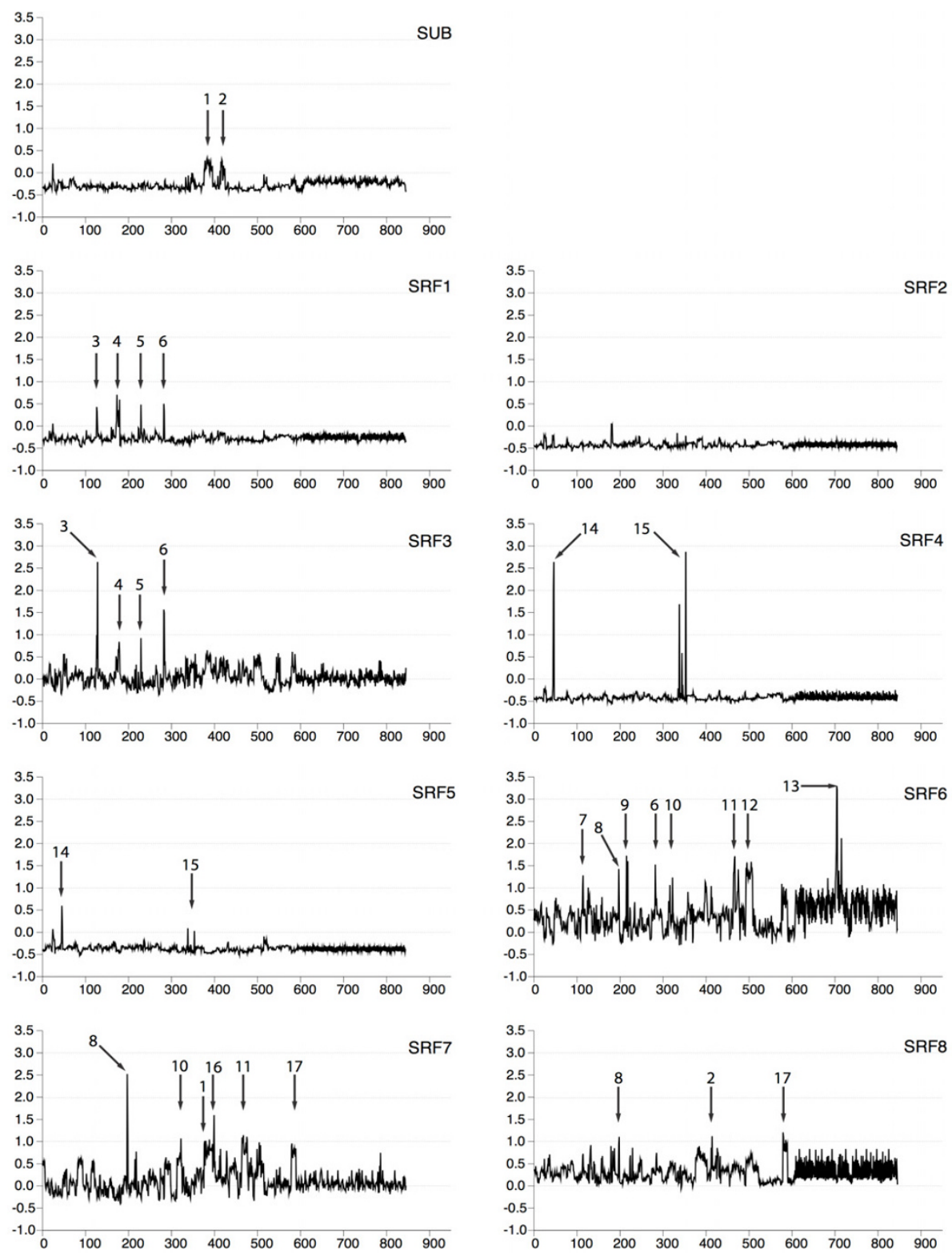

\section{Figure 8}

Microarray-based expression profiles of SRF genes. $X$ - and $Y$-axis indicate (arbitrary) chip numbers and normalized expression levels, respectively. Normalised expression levels were scaled to mean 0 and variance I. Gene names are shown at the right top corner for each profile plot. SRF3, SRF6, SRF7 and SRF8 are expressed in a large number of experiments while other SRFs show salient expression levels in specific experiments. Expression peaks are marked by an arrow and a number indicating the design type of the experiment (number in squared brackets refer to NASCArrays Experiment Reference Number): (1) developmental series ecotypes and mutants [No.155], (2) developmental series shoots and stems [No. 153], (3) programmed cell death [No.30], (4) control of lignification [No. I4], (5) tumor development [No.43], (6) pectin biosynthesis [No.27], (7) arbuscular mycorrhizal signalling [No.35], (8) AtrohbC mutant [No.42], (9) AOS burst in response to heat [No.79], (10) brassinosteroide timecourse [No.179], (I I) effect of brassinosteroides in det2 mutants and wildtype [No.I78], (I2) light treatments [No. I24], (I3) heat stress time course [No. I46], (14) transcriptional analysis of microgametogenesis [No.48], (I5) developmental series flowers and pollen [No.I52], (16) developmental series roots [No.I5I], (I7) response to sulfate limitations [No.I7I]. Arrows point either towards a single or several conditions of one experimental design for which pronounced expression levels have been detected. The arrows represent a selection of conditions that are unique characteristics of either one SRF or a SRF subgroup. 
Table 7: Enrichment of functional categories within the top 100 genes correlated to SRF genes

\begin{tabular}{|c|c|c|c|}
\hline SRF & GO ID & GO description & P-value \\
\hline \multirow[t]{4}{*}{ SRF3 } & GO:0005887 & integral to plasma membrane & 4.00E-04 \\
\hline & GO:0007030 & golgi organization and biogenesis & $4.08 \mathrm{E}-02$ \\
\hline & GO:001005I & vascular tissue pattern formation) $(*)$ & $6.36 \mathrm{E}-02$ \\
\hline & GO:0030I26 & COPI vesicle coat $(*)$ & $6.36 \mathrm{E}-02$ \\
\hline \multirow[t]{6}{*}{ SRF4 } & GO:0004672 & protein kinase activity & $3.27 \mathrm{E}-05$ \\
\hline & GO:0004674 & protein serine/threonine kinase activity & $2.90 \mathrm{E}-04$ \\
\hline & GO:0006468 & protein amino acid phosphorylation & $8.36 \mathrm{E}-04$ \\
\hline & GO:0004857 & enzyme inhibitor activity & $8.18 \mathrm{E}-03$ \\
\hline & GO:0030599 & pectinesterase activity & 3.15E-02 \\
\hline & GO:0016301 & kinase activity & 4. $19 \mathrm{E}-02$ \\
\hline \multirow[t]{5}{*}{ SRF6 } & GO:003I 225 & anchored to membrane & I.42E-03 \\
\hline & GO:000962I & response to pathogenic fungi & I.78E-03 \\
\hline & GO:0007267 & cell-cell signaling & I.23E-02 \\
\hline & GO:0012505 & endomembrane system & I.74E-02 \\
\hline & GO:0048046 & apoplast & $3.16 \mathrm{E}-02$ \\
\hline \multirow[t]{16}{*}{ SRF7 } & GO:0009833 & primary cell wall biosynthesis & I.I4E-06 \\
\hline & GO:0005618 & cell wall & $2.33 \mathrm{E}-05$ \\
\hline & GO:0016759 & cellulose synthase activity & I.9IE-04 \\
\hline & GO:0030244 & cellulose biosynthesis & $2.85 \mathrm{E}-04$ \\
\hline & GO:0012505 & endomembrane system & 3.64E-04 \\
\hline & GO:0009832 & cell wall biosynthesis (sensu Magnoliophyta) & 6.73E-04 \\
\hline & GO:0016762 & xyloglucan:xyloglucosyl transferase activity & $5.34 \mathrm{E}-03$ \\
\hline & GO:00084I5 & acyltransferase activity & $9.48 \mathrm{E}-03$ \\
\hline & GO:000400I & adenosine kinase activity & $9.96 \mathrm{E}-03$ \\
\hline & GO:0006169 & adenosine salvage & $9.96 \mathrm{E}-03$ \\
\hline & GO:003I225 & anchored to membrane & I.5IE-02 \\
\hline & GO:0016798 & hydrolase activity, acting on glycosyl bonds & $2.18 \mathrm{E}-02$ \\
\hline & GO:0005886 & plasma membrane & 2.24E-02 \\
\hline & GO:0007I55 & cell adhesion & 3.57E-02 \\
\hline & GO:0004379 & glycylpeptide $\mathrm{N}$-tetradecanoyltransferase activity & $3.96 \mathrm{E}-02$ \\
\hline & GO:0009826 & unidimensional cell growth & 4.7IE-02 \\
\hline \multirow[t]{2}{*}{ SRF8 } & GO:000460I & peroxidase activity & $1.13 \mathrm{E}-02$ \\
\hline & GO:0016126 & sterol biosynthesis & 4.59E-02 \\
\hline
\end{tabular}

Right column shows Bonferroni-corected p-values for significance of over-representation. P-values $<0.05$ were considered significant.

It remains to be seen if SRF4 affects cell proliferation, cell size, or a combination of both, and whether or not SRF4 participates in the control of the leaf size checkpoint. It is possible that SRF4 may affect plate meristem activity given that the leaf index (ratio of length over width) remains constant across srf4 mutants, wild type, and 35S::SRF4 transgenic plants. Furthermore, SRF4 might be involved in cell size control as GO term enrichment analysis among genes coexpressed with SRF4 hints at SRF4 being part of a mechanism inolving pectinesterase activity. It will be interesting to determine how SRF4 relates to the known mechanisms regulating leaf size.

\section{Functions of other SRF genes}

What is the function of the other SRF genes and is there redundancy due to functional overlap between individual $S R F$ genes in this gene family? At present we cannot provide definitive answers to these questions. SUB/SCM affects the orientation of the cell division plane and cell number in many plant tissues [29] (Ram Kishor Yadav,
Martine Batoux and K.S., unpublished observations), and influences root hair patterning [30,31]. What about the functions of the other SRF genes? Ectopic expression of several $S R F$ genes interferes with normal development and can result in seedling lethality or male sterility due to aberrant pollen development. Regarding the analysis of the loss-of-function mutants subtle phenotypes may have been overlooked or mutants are yet to be exposed to the appropriate environmental conditions. In addition, particularly in the case of SRFG, SRF7 and SRF8 sufficient SRF activity could still be present in the analysed T-DNA insertion lines.

The SRF gene family may also be characterised by a level of redundancy among family members, as demonstrated in several gene families encoding RLKs [12$15,22,23,25,26,107]$. Several lines of investigations, while each not conclusive in its own right, provide a tentative basis for this type of redundancy to play a subordinate role in the SRF gene family. Sequence differences, such as 
the variable, sometimes proline-rich, proximal ECD region flanked by the sixth LRR domain and the TM domain, the differences in the JM and alterations in the activation segments and the C-termini, could be interpreted that many of the predicted SRF proteins carry out separate functions. In addition, results from global pairwise $S R F$ coexpression analysis do not support the notion of redundancy among SRF family members. As far as sequence conservation and expression profiles are concerned the gene pairs $S R F 1 / 3, S R F 4 / 5$ and $S R F 6 / 7$ may represent exceptions. However, with the exception of altered leaves in srf4 mutants, we did not observe obvious phenotypes in the corresponding single and double mutants. In particular, the leaves of srf5 looked normal. In addition, SRF4 and SRF5 feature different C-termini, the members of the three gene pairs differ in the GO term enrichments in the groups of coexpressed genes, and SRFG and SRF7 exhibit varying expression profiles. Finally, the failure of 35S::SRF1-8 constructs to rescue the sub-1 phenotype suggests that none of the tested genes can functionally replace SUB. Thus, the combined available evidence indicates that $S R F$ genes exhibit diversity at the functional level.

What then are the hypothetical roles of $S R F$ genes? Global expression profiling and the analysis of the enrichment of GO terms among genes coexpressed with SRF genes revealed possible functions for some of the SRF genes. Several SRF genes may be involved in cell wall biosynthesis and/or function. For example, expression profiling of $S R F 1$ and SRF3 suggests a role for these genes in lignification and pectin biosynthesis. SRF3 may also have a function in the cell biology of the Golgi system and in vascular tissue pattern formation. SRF4 may be involved in a process requiring pectinesterase activity. SRFG could play a role in the defense response against pathogenic fungi. Expression profiling of SRFG also raises the possibility that this gene may be involved in stress-related processes including responses to heat and light. The $\operatorname{srf} 6$ and $s r f 7$ single mutants, and srf6 srf7 double mutants, were subjected to a set of heat-stress-related assays. However, no aberrant phenotypes were detected at the plant level (Jane Larkindale and Elizabeth Vierling, personal communication). The lack of phenotype may be due to remaining wild type SRFG and SRF7 activities in those lines (see above). It is still possible, however, that srf6 or srf7 mutants exhibit defects that can only be detected by biochemical or cell biological assays.

The GO-term analysis of SRF7 raises the possibility that SRF7 may act in primary cell wall biosynthesis and processes requiring cellulose synthase activity. SRF8 may be involved in sterol biosynthesis. Perhaps this explains the seedling lethality in 35S::SRF8 plants as sterol biosynthesis is required for embryo and seedling development
[108-114]. Recently, evidence emerged indicated a link between sterol biosynthesis, cellulose synthesis and the building of a cell wall $[115,116]$. Future experiments will test some of these indicators regarding $S R F$ function.

\section{Conclusion}

We studied the function of the $L R R-V / S R F$ gene family encoding putative LRR-RLKs. The genetic analysis of SRF4 indicates a function in the control of leaf size. With the exception of plants defective in SUB/SCM and SRF4 activity, srf single mutants, and several double-mutant combinations, did not show obvious phenotypes making it difficult to infer gene function. Results from sequence comparisons and global $S R F$ coexpression analyses are compatible with the view that redundancy among members does not play a major role in this gene family. New assays for SRF function need to take into account novel information obtained from various sources. For example, the bioinformatic analysis of microarray expression profiles and GO term enrichments among coexpressed genes raises the possibility that some of the SRF genes may relate to several aspects of cell wall biology. This work provides a basis for future analysis of $S R F$ function.

\section{Methods \\ Plant work and genetics}

Arabidopsis thaliana (L.) Heynh. var. Columbia (Col-0) and var. Landsberg (erecta mutant) (Ler) were used as wild-type strains. The sub-1 mutant was described previously [29]. Plants were grown in a greenhouse under Philips SON-T Plus 400 Watt fluorescent bulbs on a long day cycle (16 hrs light). Dry seeds were sown on soil (Patzer Einheitserde, extra-gesiebt, Typ T, Patzer GmbH \& Co. KG, Sinntal-Jossa, Germany) situated above a layer of perlite, stratified for 4 days at $4{ }^{\circ} \mathrm{C}$, and then placed in the greenhouse. The plants were kept under a lid for the next 7-8 days to increase humidity and support equal germination. T-DNA insertion lines for all SRF genes were obtained from various sources including SIGnAL [117], the University of Wisconsin Knockout facility [118], SAIL (Syngenta Biotechnology, Research Triangle Park, NC, USA) [119], and GABI-KAT [120]. Except for srf7-2 (ecotype Wassilewskija, Ws) all T-DNA insertion mutations are in the Col background. Genomic DNA of wild-type and different T-DNA insertion lines was isolated according to standard procedures. The insertion lines were screened by a PCR-based approach with corresponding TDNA-specific and gene-specific primers.

Homozygous T-DNA insertion lines were confirmed by a different gene-specific primer set. Double mutants were generated by crossing confirmed single mutants, selfing of the F1 plants, and PCR-based progeny testing in the F2. A detailed summary is given in Additional file 1. Confirmed single T-DNA insertion mutants in Col background were 
also introduced into the Ler background by crossing single mutants with Ler, F1 selfing, and F2 progeny testing for homozygous srf T-DNA insertions and homozygous er background. Morphological inspection of single mutant (either in Col or Ler backgrounds) and double-mutant (Col background) plants was done with plants grown in the greenhouse under regular growth conditions. The following single mutants were used in the analysis: srf1-2, srf1-3, srf1-7, srf2-1, srf2-3, srf3-1, srf3-3, srf3-7, srf4-2, srf4-

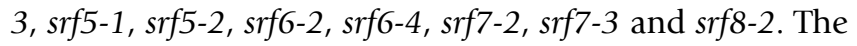
following double mutants were analysed: srf1-3 srf3-1, srf4-2 srf5-1, srf4-3 srf5-1, srf4-3 srf5-2, srf6-2 srf7-2, srf6-2 srf7-3. More detailed information regarding the lines is given in Additional file 1.

To avoid crowding artefacts plants were sown at a maximum density of 5 plants per pot $(7 \mathrm{~cm} \times 7 \mathrm{~cm})$. Following planting, individual plants were inspected for morphological alterations every two days. Assayed traits included hypocotyl length, number, size and shape of rosette leaves, trichome morphology, flowering time, stem morphology, flower morphology (including ovules and pollen), fertility, and seed size and shape. To analyse germination behavior and root development, dry seeds of wild-type, single and double-mutants were surface-sterilized, plated on $0.9 \%$ agar plates containing $0.5 \times$ Murashige and Skoog medium [121] supplemented with $1 \%$ sucrose, stratified for 4 days at $4{ }^{\circ} \mathrm{C}$, and then moved to a cell-culture room kept at $22^{\circ} \mathrm{C}$ and $24 \mathrm{hrs}$ light. Plates were placed vertically next to vertically arranged fluorescent bulbs. Root growth was assayed after 10 days. Leaf blade measurements were done using images of dissected fifth rosette leaves that had been scanned into the computer and with the help of ImageJ software [122].

\section{Molecular work, DNA sequencing and cDNA isolation}

For DNA and RNA work standard molecular biology techniques were used [123]. Sequences were obtained by standard cycle sequencing using an $\mathrm{ABI} 373$ sequencer (PE Applied Biosystems). PCR products, genomic and cDNA clones were sequenced on both strands. Additional $5^{\prime}$ and 3 ' ends were obtained through a rapid amplification of cDNA ends approach [124] using the Marathon kit (CLONTECH) and poly(A)+ RNA (Col) from flowers of stages 1-12 [125] (SRF1A/B to SRF5, SRF7-8) or rosette leaves (SRFG). The various SRF full-length cDNA sequences have been deposited at GenBank. For a summary see Table 1. For a list of primers see Additional file 1.

\section{Developmental expression profile of SRF genes by RT- PCR}

Cauline and rosette leaves were harvested from 31 days old plants. Stage 1-12 flowers (stages according to [125]), siliques and stems were collected from 30 to 38 days old plants, roots from 14 days old plants grown on standard
MS-agar plates, and seedlings were taken at 14 days. Primers were taken from the SRF sequences that flank the transmembrane domains. This region is very variable between the different $S R F$ genes. The exception is $S R F 1$ for which primers were chosen that reside in the region encoding the juxtramembrane domain. PCR conditions included the following parameters: denaturation at $94^{\circ} \mathrm{C}$ for 1 minute, annealing at gene-specific annealing temperature, elongation at $72^{\circ} \mathrm{C}$ for 1 minute, 40 cycles, final extension at $72^{\circ} \mathrm{C}$ for 2 minutes. The GAPC gene was used as control [126].

\section{Computer-based sequence analysis}

Homology searches were done with the BLAST tool [127]. The signal peptide sequences, the proline-rich regions, the transmembrane domains, and the PEST motifs were determined using the SMART [128], PROSITE [129], PSORT [130], and PESTfind [131] websites. The kinase domains were detected through the PlantsP database [132]. The subdomain organisation of the kinase domains was inferred from published kinase alignments [38]. Sequence alignments were done with MultAlin $[133,134]$ using the following parameters: symbol comparison table: identity, gap weight: 5, gap length weight: 0 , consensus levels: high $=100 \%$ low $=60 \%$. Phylogenetic tree analysis of the SRF family was performed using an amino acid sequence alignment generated by the program DAMBE [135] using a gap penalty value of 20 . Using this alignment a maximum likelihood tree was generated in TREE-PUZZLE [136] with the help of the JTT model of substitution. Rate heterogeneity was estimated with the gamma distribution model with eight rate categories as described in [137]. We also tested different approaches (Baysian inference, Neighbor-joining) but the topology of the tree did not change. TREEVIEW was used to visualise the tree [138].

\section{Overexpression of SRF genes}

The full length $S R F$ open reading frames (ORFs) were amplified from individual full-length $S R F$ cDNA clones by PCR. The SRF ORFs were cloned in sense orientation into a modified version of the plant transformation vector pCAMBIA2300 [139]. The modified pCAMBIA2300 vector includes a $3 \times$ myc tag and allows the generation of SRF proteins that are tagged with a $3 \times$ myc-tag at their carboxy ends (Ram Kishor Yadav and K.S., unpublished work). To this end, we cloned the PCR fragments into the $5^{\prime}$ AscI and 3' AatII sites except for SRF2 and SRF5, for which we used $A p a I$ at the 3' end. The various SRF:myc ORFs are flanked $5^{\prime}$ by the CaMV 35S promoter and 3' by a nopaline synthase transcription termination signal. The Agrobacterium strain GV3101 was used for plant transformation [140] using the floral dip method [141]. For 35S::SRF1B:myc and 35S::SRF2 to 35S::SRF7:myc at least 50 transgenic T1 sub-1 (in Ler background), Ler, and Col plants were 
selected on kanamycin plates $(50 \mu \mathrm{g} / \mathrm{ml})$ and then transferred to soil.

Transgene expression in at least 5 lines of each experiment was confirmed by RT-PCR using a gene-specific primer and a myc-tag-derived primer. In the case of 35S::SRF1A:myc, the majority of $\mathrm{T} 1$ plants died at the 2cotyledon stage, irrespective of the background (sub-1, Ler, and Col). We managed, however, to isolate 11 (in sub-1 background), 38 (Ler), and 29 (Col) T1 survivors. We tested 7 (sub-1), 8 (Ler) and 5 (Col) 35S::SRF1A:myc T1 lines positive in RT-PCR assays for transgene expression. No apparent modification of either the sub-1 or wild-type phenotype was observed in those $\mathrm{T} 1$ plants. The 35S::SRF8: $m y c$ T1 plants exhibited a similar lethality at the 2 -cotyledon stage. Again a few T1 plants escaped the seedling lethality (20 (sub-1), 58 (Ler) and 20 (Col)). We could detect transgene expression by RT-PCR in 5 (sub-1), 14 (Ler), 3 (Col) T1 plants, respectively. No apparent modification of either the sub-1 or wild-type phenotype was observed in those $\mathrm{T} 1$ plants either.

\section{Microscopy and art work}

Pictures of plants or various plant organs were taken with an SZX12 stereo microscope from Olympus coupled to a ColorView III digital camera and using Cell^^ (Olympus Europa GmbH, Hamburg, Germany). Images were saved as TIFF files and adjusted for color and contrast using Adobe Photoshop CS2 (Adobe, San Jose, CA, USA) software on an iMac G5 computer (Apple, Cupertino, CA, USA). Composites were also generated by Adobe Photoshop CS2. Line drawings were generated using Adobe Illustrator CS2.

\section{Microarray analysis}

Microarray data were obtained from the NASC Affywatch service (CD-ROM release as of June, 2005; [142]). To avoid complications from the comparison between different platforms, we only used measurements from the Affymetrix ATH1 GeneChip platform. Probe sets were recalculated according to the following scheme: all oligonucleotides present on the ATH1 GeneChip of Affymetrix (sequences downloaded from [143] as of October 2004) were mapped on the whole genome sequence (MAtDB release from $24^{\text {th }}$ of September, 2004, [144]) and realigned against coding sequences. UTR sequences were included if the respective gene is associated with full length cDNA information. Oligonucleotides aligning to more than one gene and probes without perfect matches were excluded. For subsequent calculations, only probe sets with at least five unique probe pairs were considered. About $10 \%$ of the original probe sets led to unspecific estimates indicating the need for the re-alignments. We excluded those probe sets from our refined sets. In sum- mary expression measurements from 21,559 genes met the quality criteria and were used for subsequent analysis.

For statistical analysis of the expression data we applied the FunDaMiner system [145]. We calculated probe set summaries for the complete dataset using MAS 5.0, dChip [146] and RMA [147]. The complete dataset was normalized by applying the LMPN method. LMPN is based on the local polynomial regression fitting method loess $[148,149]$ operating on MA-scale [150]. For the correlation analysis we summarized replicates (usually 3 ) by the arithmetic mean. For 1784 measurements, i.e. microarray experiments, we computed the correlation matrix of allagainst all probe sets. Correlations were determined as metric (Pearson) correlation coefficients. To investigate expression profiles for each $S R F$ gene within in this expression data set, we determined for each experiment its mean and standard deviation $(\sigma)$. Expression values in the plots are expressed as fold $\sigma$ difference to the mean.

\section{Enrichment for GO categories}

GOslim annotations for Arabidopsis were obtained from TAIR [37]. For our analysis, we considered solely GO annotations derived from the ontology describing biological processes. Gene lists were matched with the 21,559 genes analyzed in this study. GO terms annotated only once in the genome were not considered. To determine whether a set of genes correlated to a particular SRF is enriched for a specific GO term, we tested for its statistical overrepresentation within the set compared to the background (whole genome) expectation. P-values were obtained for each GO category present in the set by cumulative binomial probability:

$$
P(k \geq x)=\sum_{k-x}^{n}\left(\begin{array}{l}
n \\
k
\end{array}\right) p^{k}(1-p)^{n-k}
$$

where $\mathrm{n}$ is the number of all studied genes associated with a specific GO annotation, $x$ is the number of observed genes correlated to a particular SRF and associated with this GO annotation, and $p$ is the genomic frequency of this GO annotation, i.e. the number of genes annotated for this GO identifier divided by the number of all studied genes. P-values were Bonferroni-corrected for multiple hypothesis testing. For each SRF, the total number of tests corresponded to the number of different GO annotations of its correlated gene set.

\section{Authors' contributions}

$\mathrm{BE}, \mathrm{KP}, \mathrm{GH}, \mathrm{DC}$ and $\mathrm{AF}$ designed and performed experiments. KS conceived the study. KFXM and KS designed and coordinated the study. GH and KS wrote the paper. All authors read and approved the final manuscript. 


\section{Additional material}

\section{Additional file 1}

Supplement. A Microsoft Excel file with a description of srf T-DNA insertion lines and a complete list of primer sequences.

Click here for file

[http://www.biomedcentral.com/content/supplementary/14712229-7-16-S1.xls]

\section{Acknowledgements}

We thank Lynette Fulton and Sureshkumar Balasubramanian for critical reading of the manuscript. We also thank members of the Schneitz lab for stimulating discussions. This work was funded by the Arabidopsis Functional Genomics Network (AFGN/NSF2010) through grants SCHN 723/2I and SCHN 723/2-2 from the German Research Council (DFG) to KS, by an EMBO young investigator (EMBO-YIP) fellowship to $\mathrm{KS}$, and by the Free State of Bavaria. Work at MIPS (GH and KFXM) was funded by the GABI program of the German Ministry of Education and Research (BMBF).

\section{References}

I. Walker JC, Zhang R: Relationship of a putative receptor protein kinase from maize to the S-locus glycoprotein of Brassica. Nature 1990, 345:743-746.

2. Becraft PW: Receptor kinase signaling in plant development. Annu Rev Cell Dev Biol 2002, I8:163-192.

3. Diévart A, Clark SE: LRR-containing receptors regulating plant development and defense. Development 2004, I 31 :25I-26I.

4. Haffani YZ, Silva NF, Goring DR: Receptor kinase signalling in plants. Can J Bot 2004, 82: I-I5.

5. Morris ER, Walker JC: Receptor-like protein kinases: the keys to response. Curr Opin Plant Biol 2003, 6:339-342.

6. Torii KU: Leucine-rich repeat receptor kinases in plants: structure, function, and signal transduction pathways. Int Rev Cytol 2004, 234: I-46.

7. Shiu S-H, Bleecker AB: Receptor-like kinases from Arabidopsis form a monophyletic gene family related to animal receptor kinases. Proc Natl Acad of Sci USA 200 I, 98: 10763-10768.

8. Shiu SH, Bleecker AB: Expansion of the receptor-like kinase/ Pelle gene family and receptor-like proteins in Arabidopsis. Plant Physiol 2003, 132:530-543.

9. Kobe $B$, Kajava AV: The leucine-rich repeat as a protein recognition motif. Curr Opin Struct Biol 200I, II:725-732.

10. Canales C, Bhatt AM, Scott R, Dickinson H: EXS, a putative LRR receptor kinase, regulates male germline cell number and tapetal identity and promotes seed development in Arabidopsis. Curr Biol 2002, I 2:1718-1727.

11. Zhao DZ, Wang GF, Speal B, Ma H: The excess microsporocytes I gene encodes a putative leucine-rich repeat receptor protein kinase that controls somatic and reproductive cell fates in the Arabidopsis anther. Genes Dev 2002, I6:202I-203I.

12. Albrecht C, Russinova E, Hecht V, Baaijens E, de Vries S: The Arabidopsis thaliana SOMATIC EMBRYOGENESIS RECEP. TOR-LIKE KINASESI and 2 control male sporogenesis. Plant Cell 2005, 17:3337-3349.

13. Colcombet ], Boisson-Dernier A, Ros-Palau R, Vera CE, Schroeder II: Arabidopsis SOMATIC EMBRYOGENESIS RECEPTOR KINASES I and 2 are essential for tapetum development and microspore maturation. Plant Cell 2005, I7:3350-336I.

14. Hord CL, Chen C, Deyoung BJ, Clark SE, Ma H: The BAMI/BAM2 Receptor-Like Kinases Are Important Regulators of Arabidopsis Early Anther Development. Plant Cell 2006, 18:1667-1680.

15. DeYoung BJ, Bickle KL, Schrage KJ, Muskett P, Patel K, Clark SE: The CLAVATAI-related BAMI, BAM2 and BAM3 receptor kinase-like proteins are required for meristem function in Arabidopsis. Plant J 2006, 45: I- 16.
16. Li J: Brassinosteroid signaling: from receptor kinases to transcription factors. Curr Opin Plant Biol 2005, 8:526-53I.

17. Vert G, Nemhauser JL, Geldner N, Hong F, Chory J: Molecular mechanisms of steroid hormone signaling in plants. Annu Rev Cell Dev Biol 2005, 21: I77-201.

18. Li JM, Chory J: A putative leucine-rich repeat receptor kinase involved in brassinosteroid signal transduction. Cell 1997. 90:929-938

19. Kinoshita T, Caño-Delgado A, Seto H, Hiranuma S, Fujioka S, Yoshida $\mathrm{S}$, Chory J: Binding of brassinosteroids to the extracellular domain of plant receptor kinase BRII. Nature 2005, 433: $167-|7|$.

20. Wang Z-Y, Seto H, Fujioka S, Yoshida S, Chory J: BRI is a critical component of a plasma-membrane receptor for plant steroids. Nature 2001, 410:380-383.

2I. Clay NK, Nelson T: VHI, a provascular cell-specific receptor kinase that influences leaf cell patterns in Arabidopsis. Plant Cell 2002, I 4:2707-2722.

22. Caño-Delgado A, Yin Y, Yu C, Vafeados D, Mora-García S, Cheng JC, $\mathrm{Nam} \mathrm{KH}, \mathrm{Li}$ J, Chory J: BRLI and BRL3 are novel brassinosteroid receptors that function in vascular differentiation in Arabidopsis. Development 2004, 131:534I-535I.

23. Zhou A, Wang H, Walker JC, Li J: BRLI, a leucine-rich repeat receptor-like protein kinase, is functionally redundant with BRII in regulating Arabidopsis brassinosteroid signaling. Plant J 2004, 40:399-409.

24. Friedrichsen DM, Joazeiro CAP, Li J, Hunter T, Chory J: Brassinosteroid-insensitive- $I$ is a ubiquitously expressed leucine-rich repeat receptor serine/threonine kinase. Plant Physiol 2000, 123:1247-1255

25. Shpak ED, Berthiaume CT, Hill EJ, Torii KU: Synergistic interaction of three ERECTA-family receptor-like kinases controls Arabidopsis organ growth and flower development by promoting cell proliferation. Development 2004, I3 I:|49|-I50|.

26. Shpak ED, McAbee JM, Pillitteri LJ, Torii KU: Stomatal patterning and differentiation by synergistic interactions of receptor kinases. Science 2005, 309:290-293.

27. Torii KU, Mitsukawa N, Oosumi T, Matsuura Y, Yokoyama R, Whittier RF, Komeda $\mathrm{Y}$ : The Arabidopsis ERECTA gene encodes a putative receptor protein kinase with extracellular leucinerich repeats. Plant Cell 1996, 8:735-746.

28. Schneitz K, Hülskamp M, Kopczak SD, Pruitt RE: Dissection of sexual organ ontogenesis: a genetic analysis of ovule development in Arabidopsis thaliana. Development 1997, 124: I367-1376.

29. Chevalier D, Batoux M, Fulton L, Pfister K, Yadav RK, Schellenberg M, Schneitz K: STRUBBELIG defines a receptor kinase-mediated signaling pathway regulating organ development in Arabidopsis. Proc Natl Acad Sci USA 2005, 102:9074-9079.

30. Kwak SH, Schiefelbein J: The role of the SCRAMBLED receptorlike kinase in patterning the Arabidopsis root epidermis. Dev Biol 2007, 302: || $8-13 \mid$.

31. Kwak SH, Shen R, Schiefelbein J: Positional signaling mediated by a receptor-like kinase in Arabidopsis. Science 2005, 307:1111-1113.

32. Kroiher M, Miller MA, Steele RE: Deceiving appearances: signaling by "dead" and "fractured" receptor protein-tyrosine kinases. Bioessays 200I, 23:69-76.

33. Arabidopsis Strubbelig Receptor Gene Family [http:// www.arabidopsis.org/browse/genefamily/lrrv.jsp]

34. Li Z, Wurtzel ET: The Itk gene family encodes novel receptorlike kinases with temporal expression in developing maize endosperm. Plant Mol Biol 1998, 37:749-76I.

35. Blanc G, Hokamp K, Wolfe $\mathrm{KH}$ : A recent polyploidy superimposed on older large-scale duplications in the Arabidopsis genome. Genome Res 2003, 13:137-144.

36. MIPS Arabidopsis thaliana Database [http://mips.gsf.de/proj/ plant/sf/athal/index.jsp]

37. The Arabidopsis Information Resource [http://www.arabidop sis.org]

38. Hanks SK, Quinn AM: Protein kinase catalytic domain sequence database: identification of conserved features of primary structure and classification of family members. Methods in Enzymology 1991, 200:38-62.

39. Scheeff ED, Bourne PE: Structural evolution of the protein kinase-like superfamily. PLoS Comput Biol 2005, I:e49. 
40. Huse M, Kuriyan J: The conformational plasticity of protein kinases. Cell 2002, 109:275-282.

4I. Johnson LN, Noble MEM, Owen DJ: Active and inactive protein kinases: structural basis for regulation. Cell 1996, 85:149-158.

42. Nühse TS, Stensballe A, Jensen ON, Peck SC: Phosphoproteomics of the Arabidopsis plasma membrane and a new phosphorylation site database. Plant Cell 2004, 16:2394-2405.

43. Jeong S, Trotochaud AE, Clark SE: The Arabidopsis CLAVATA2 gene encodes a receptor-like protein required for the stability of the CLAVATAI receptor-like kinase. Plant Cell I999, II:1925-1934

44. Jones DA, Thomas CM, Hammond-Kosack KE, Balint-Kurti PJ, Jones JD: Isolation of the tomato Cf-9 gene for resistance to Cladosporium fulvum by transposon tagging. Science 1994, 266:789-793.

45. Nadeau JA, Sack FD: Control of stomatal distribution on the Arabidopsis leaf surface. Science 2002, 296:1697-1700.

46. Tör M, Brown D, Cooper A, Woods-Tor A, Sjölander K, Jones JD, Holub EB: Arabidopsis downy mildew resistance gene RPP27 encodes a receptor-like protein similar to CLAVATA2 and tomato Cf-9. Plant Physiol 2004, I 35: I I00-I I I 2

47. Nordborg M, Hu TT, Ishino Y, Jhaveri J, Toomajian C, Zheng H, Bakker E, Calabrese P, Gladstone J, Goyal R, et al: The pattern of polymorphism in Arabidopsis thaliana. PLOS Biol 2005, 3:el 96.

48. Tsuge $T$, Tsukaya $H$, Uchimiya $H$ : Two independent and poarized processes of cell elongation regulate leaf blade expansion in Arabidopsis. Development 1996, I22:1589-1600.

49. Odell JT, Nagy F, Chua NH: Identification of DNA sequences required for activity of the cauliflower mosaic virus $35 \mathrm{~S}$ promoter. Nature 1985, 313:810-812.

50. Craigon DJ, James N, Okyere J, Higgins J, Jotham J, May S: NASCArrays: a repository for microarray data generated by NASC's transcriptomics service. Nucleic Acids Res 2004, 32:D575-577.

5I. Schmid M, Davison TS, Henz SR, Pape UJ, Demar M, Vingron M, Scholkopf B, Weigel D, Lohmann JU: A gene expression map of Arabidopsis thaliana development. Nat Genet 2005, 37:50I-506.

52. Becker JD, Boavida LC, Carneiro J, Haury M, Feijo JA: Transcriptional profiling of Arabidopsis tissues reveals the unique characteristics of the pollen transcriptome. Plant Physiol 2003, I33:7| 3-725.

53. Schiefelbein J, Somerville C: Genetic control of root hair development in Arabidopsis thaliana. Plant Cell 1990, 2:235-243.

54. DeRisi JL, lyer VR, Brown PO: Exploring the metabolic and genetic control of gene expression on a genomic scale. Science 1997, 278:680-686.

55. Hughes TR, Marton MJ, Jones AR, Roberts CJ, Stoughton R, Armour $\mathrm{CD}$, Bennett HA, Coffey E, Dai H, He YD, et al.: Functional discovery via a compendium of expression profiles. Cell 2000, 102:109-126.

56. Rautengarten C, Steinhauser D, Büssis D, Stintzi A, Schaller A, Kopka J, Altmann T: Inferring hypotheses on functional relationships of genes: analysis of the Arabidopsis thaliana subtilase gene family. PLoS Comput Biol 2005, I:e40.

57. Berardini TZ, Mundodi S, Reiser L, Huala E, Garcia-Hernandez M, Zhang P, Mueller LA, Yoon J, Doyle A, Lander G, et al.: Functional annotation of the Arabidopsis genome using controlled vocabularies. Plant Physiol 2004, 135:745-755.

58. Fritz-Laylin LK, Krishnamurthy N, Tör M, Sjölander KV, Jones JD: Phylogenomic analysis of the receptor-like proteins of rice and Arabidopsis. Plant Physiol 2005, 1 38:6 I I-623.

59. Giranton JL, Ariza MJ, Dumas C, Cock JM, Gaude T: The S locus receptor kinase gene encodes a soluble glycoprotein corresponding to the SKR extracellular domain in Brassica oleracea. Plant J 1995, 8:827-834.

60. Suzuki G, Watanabe M, Toriyama K, Isogai A, Hinata K: Expression of SLG9 and SRK9 genes in transgenic tobacco. Plant and Cell Physiology 1996, 37:866-869.

61. Dixon MS, Jones DA, Keddie JS, Thomas CM, Harrison K, Jones JD: The tomato $\mathrm{Cf}-2$ disease resistance locus comprises two functional genes encoding leucine-rich repeat proteins. Cell 1996, 84:45|-459.

62. Nasrallah JB, Kao T-H, Goldberg ML, Nasrallah ME: A cDNA clone encoding an S-locus-specific glycoprotein from Brassica oleracea. Nature 1985, 3 1 8:263-267.

63. Wang GL, Ruan DL, Song WY, Sideris S, Chen L, Pi LY, Zhang S, Zhang $Z$, Fauquet $C$, Gaut BS, et al:: Xa2 ID encodes a receptor- like molecule with a leucine-rich repeat domain that determines race-specific recognition and is subject to adaptive evolution. Plant Cell 1998, 10:765-779.

64. Song W-Y, Wang G-L, Chen L-L, Kim H-S, Pi L-Y, Holsten T, Gardner J, Wang B, Zhai W-X, Zhu L-H, et al.: A receptor kinase-like protein encoded by the rice resistance gene, $\mathrm{Xa2} I$. Science 1995 , 270:1804-1806.

65. Wang GL, Song WY, Ruan DL, Sideris S, Ronald PC: The cloned gene, $\mathrm{Xa2}$ I, confers resistance to multiple $X$ anthomonas oryzae pv. oryzae isolates in transgenic plants. Mol Plant Microbe Interact 1996, 9:850-855.

66. Kayes JM, Clark SE: CLAVATA2, a regulator of meristem and organ development in Arabidopsis. Development 1998, I 25:3843-385 I.

67. Trotochaud AE, Hao T, Wu G, Yang Z, Clark SE: The CLAVATAI receptor-like kinase requires CLAVATA3 for its assembly into a signaling complex that includes KAPP and a Rhorelated protein. Plant Cell I999, I I:393-406.

68. Kemp BP, Doughty J: Just how complex is the Brassica S-receptor complex? J Exp Bot 2003, 54:157-168.

69. Takayama S, Isogai A: Molecular mechanism of self-recognition in Brassica self-incompatibility. J Exp Bot 2003, 54:149-156.

70. Giranton JL, Dumas C, Cock JM, Gaude T: The integral membrane S-locus receptor kinase of Brassica has serine/threonine kinase activity in a membranous environment and spontaneously forms oligomers in planta. Proc Natl Acad Sci USA 2000, 97:3759-3764.

7I. Takayama S, Shimosato H, Shiba H, Funato M, Che F-S, Watanabe M, Iwano M, Isogai A: Direct ligand-receptor complex interaction controls Brassica self-incompatibility. Nature 200I, 413:535-538.

72. Takasaki T, Hatakeyama K, Suzuki G, Watanabe M, Isogai A, Hinata $\mathrm{K}$ : The $S$ receptor kinase determines self-incompatibility in Brassica stigma. Nature 2000, 403:9|3-916.

73. Dixit R, Nasrallah ME, Nasrallah JB: Post-transcriptional maturation of the $S$ receptor kinase of Brassica correlates with coexpression of the S-locus glycoprotein in the stigmas of two Brassica strains and in transgenic tobacco plants. Plant Physiol 2000, I 24:297-3 I I.

74. Meyers BC, Kozik A, Griego A, Kuang H, Michelmore RW Genome-wide analysis of NBS-LRR-encoding genes in Arabidopsis. Plant Cell 2003, 1 5:809-834.

75. Michelmore RW, Meyers BC: Clusters of resistance genes in plants evolve by divergent selection and a birth-and-death process. Genome Res 1998, 8: III3-1 I30.

76. Richly E, Kurth J, Leister D: Mode of amplification and reorganization of resistance genes during recent Arabidopsis thaliana evolution. Mol Biol Evol 2002, 19:76-84.

77. Purugganan MD, Suddith Jl: Molecular population genetics of floral homeotic loci. Departures from the equilibrium-neutral model at the APETALA3 and PISTILLATA genes of Arabidopsis thaliana. Genetics 1999, 151:839-848.

78. Purugganan MD, Suddith JI: Molecular population genetics of the Arabidopsis CAULIFLOWER regulatory gene: nonneutral evolution and naturally occurring variation in floral homeotic function. Proc Natl Acad Sci USA 1998, 95:8I30-8I34.

79. Chisholm ST, Coaker G, Day B, Staskawicz BJ: Host-microbe interactions: shaping the evolution of the plant immune response. Cell 2006, 124:803-8|4

80. Dangl JL, Jones JD: Plant pathogens and integrated defence responses to infection. Nature 200 I, 4I I:826-833.

8I. Bakker EG, Toomajian C, Kreitman M, Bergelson J: A genome-wide survey of $\mathbf{R}$ gene polymorphisms in Arabidopsis. Plant Cell 2006, 18:1803-1818.

82. Botella MA, Parker JE, Frost LN, Bittner-Eddy PD, Beynon JL, Daniels MJ, Holub EB, Jones JDG: Three genes of the Arabidopsis RPPI complex resistance locus recognizes distinct Peronosporo parasitica avirulence determinants. Plant Cell 1998, 10:1847-1860.

83. Caicedo AL, Schaal BA, Kunkel BN: Diversity and molecular evolution of the RPS2 resistance gene in Arabidopsis thaliana. Proc Natl Acad Sci USA 1999, 96:302-306.

84. Noël L, Moores TL, van Der Biezen EA, Parniske M, Daniels MJ, Parker JE, Jones JD: Pronounced intraspecific haplotype divergence at the RPP5 complex disease resistance locus of Arabidopsis. Plant Cell 1999, I I:2099-2 I I2. 
85. Stahl EA, Dwyer G, Mauricio R, Kreitman M, Bergelson J: Dynamics of disease resistance polymorphism at the Rpm I locus of Arabidopsis. Nature 1999, 400:667-67I.

86. Tian D, Araki H, Stahl E, Bergelson J, Kreitman M: Signature of balancing selection in Arabidopsis. Proc Natl Acad Sci USA 2002, 99: II525-II530.

87. Beemster GTS, Fiorani F, Inzé D: Cell cycle: the key to plant growth control? Trends Plant Sci 2003, 8: I54-I 58.

88. Ingram GC, Waites R: Keeping it together: co-ordinating plant growth. Curr Opin Plant Biol 2006, 9:12-20.

89. Mizukami Y: A matter of size: developmental control of organ size in plants. Curr Opin Plant Biol 2001, 4:533-539.

90. Tsukaya $\mathrm{H}$ : Organ shape and size: a lesson from studies of leaf morphogenesis. Curr Opin Plant Biol 2003, 6:57-62

91. Mizukami Y, Fischer RL: Plant organ size control: AINTEGUMENTA regulates growth and cell numbers during organogenesis. Proc Natl Acad Sci USA 2000, 97:942-947.

92. Hu Y, Xie Q, Chua NH: The Arabidopsis auxin-inducible gene ARGOS controls lateral organ size. Plant Cell 2003, I5:1951-1961.

93. Elliott RC, Betzner AS, Huttner E, Oakes MP, Tucker WQJ, Gerentes D, Perez P, Smyth DR: AINTEGUMENTA, an APETALA2-like gene of Arabidopsis with pleiotropic roles in ovule development and floral organ growth. Plant Cell I996, 8: I55-I68.

94. Klucher KM, Chow H, Reiser L, Fischer RL: The AINTEGUMENTA gene of Arabidopsis required for ovule and female gametophyte development is related to the floral homeotic gene APETALA2. Plant Cell 1996, 8:137-153.

95. Weigel D: The APETALA2 domain is related to a novel type of DNA binding domain. Plant Cell 1995, 7:388-389.

96. Baker SC, Robinson-Beers K, Villanueva JM, Gaiser JC, Gasser CS Interactions among genes regulating ovule development in Arabidopsis thaliana. Genetics 1997, 145: I 109-II24.

97. Schneitz K, Baker SC, Gasser CS, Redweik A: Pattern formation and growth during floral organogenesis: HUELLENLOS and AINTEGUMENTA are required for the formation of the proximal region of the ovule primordium in Arabidopsis thaliana. Development 1998, I 25:2555-2563.

98. Krizek BA: Ectopic expression of AINTEGUMENTA in Arabidopsis plants results in increased growth of floral organs. Dev Genet 1999, 25:224-236.

99. Dewitte W, Riou-Khamlichi C, Scofield S, Healy JM, Jacqmard A, Kilby NJ, Murray JA: Altered cell cycle distribution, hyperplasia, and inhibited differentiation in Arabidopsis caused by the D-type cyclin CYCD3. Plant Cell 2003, I 5:79-92.

100. Tsukaya H: Mechanism of leaf shape determination. Annu Rev Plant Biol 2006, 57:477-496.

101. Donnelly PM, Bonetta D, Tsukaya H, Dengler RE, Dengler NG: Cell cycling and cell enlargement in developing leaves of Arabidopsis. Dev Biol 1999, 2 1 5:407-419.

102. Horiguchi G, Kim GT, Tsukaya H: The transcription factor AtGRF5 and the transcription coactivator AN3 regulate cell proliferation in leaf primordia of Arabidopsis thaliana. Plant J 2005, 43:68-78

103. $\mathrm{Kim} \mathrm{JH}$, Choi D, Kende $\mathrm{H}$ : The AtGRF family of putative transcription factors is involved in leaf and cotyledon growth in Arabidopsis. Plant J 2003, 36:94-104.

104. Kim JH, Kende $\mathrm{H}$ : A transcriptional coactivator, AtGIFI, is involved in regulating leaf growth and morphology in Arabidopsis. Proc Natl Acad Sci USA 2004, I 0 I: I 3374-I 3379.

105. Hu Y, Poh HM, Chua NH: The Arabidopsis ARGOS-LIKE gene regulates cell expansion during organ growth. Plant J 2006, 47:1-9.

106. Fujikura U, Horiguchi G, Tsukaya $\mathrm{H}$ : Dissection of enhanced cell expansion processes in leaves triggered by a defect in cell proliferation, with reference to roles of endoreduplication. Plant Cell Physiol 2007, 48:278-286.

107. Shpak ED, Lakeman MB, Torii KU: Dominant-negative receptor uncovers redundancy in the Arabidopsis ERECTA Leucinerich repeat receptor-like kinase signaling pathway that regulates organ shape. Plant Cell 2003, I 5:1095-I I I0.

108. Diener AC, Li H, Zhou W, Whoriskey WJ, Nes WD, Fink GR: Sterol methyltransferase I controls the level of cholesterol in plants. Plant Cell 2000, I 2:853-870.
109. He JX, Fujioka S, Li TC, Kang SG, Seto H, Takatsuto S, Yoshida S, Jang JC: Sterols regulate development and gene expression in Arabidopsis. Plant Physiol 2003, I3 I: I258-1269.

I I0. Jang JC, Fujioka S, Tasaka M, Seto H, Takatsuto S, Ishii A, Aida M, Yoshida S, Sheen J: A critical role of sterols in embryonic patterning and meristem programming revealed by the fackel mutants of Arabidopsis thaliana. Genes Dev 2000, I 4: | 485- | 497.

III. Schaller H: The role of sterols in plant growth and development. Prog Lipid Res 2003, 42: I63-I75.

I 12. Schrick K, Mayer U, Horrichs A, Kuhnt C, Bellini C, Dangl J, Schmidt J, Jürgens G: FACKEL is a sterol $C-14$ reductase required for organized cell division and expansion in Arabidopsis embryogenesis. Genes Dev 2000, |4:|47|-|484.

I 13. Schrick K, Mayer U, Martin G, Bellini C, Kuhnt C, Schmidt J, Jürgens $\mathrm{G}$ : Interactions between sterol biosynthesis genes in embryonic development of Arabidopsis. Plant J 2002, 3 I:6 I-73.

I 14. Souter M, Topping J, Pullen M, Friml J, Palme K, Hackett R, Grierson $D$, Lindsey $K$ : hydra Mutants of Arabidopsis are defective in sterol profiles and auxin and ethylene signaling. Plant Cell 2002, I 4:1017-1031.

I I5. Peng L, Kawagoe Y, Hogan P, Delmer D: Sitosterol-beta-glucoside as primer for cellulose synthesis in plants. Science 2002, 295: $147-150$.

I 16. Schrick K, Fujioka S, Takatsuto S, Stierhof YD, Stransky H, Yoshida S, jürgens G: A link between sterol biosynthesis, the cell wall, and cellulose in Arabidopsis. Plant J 2004, 38:227-243.

1 17. Alonso JM, Stepanova AN, Leisse TJ, Kim CJ, Chen H, Shinn P, Stevenson DK, Zimmerman J, Barajas P, Cheuk R, et al:: Genome-wide insertional mutagenesis of Arabidopsis thaliana. Science 2003 , 301:653-657

I 18. Krysan PJ, Young JK, Sussman MR: T-DNA as an insertional mutagen in Arabidopsis. Plant Cell 1999, I I:2283-2290.

I 19. Sessions A, Burke E, Presting G, Aux G, McElver J, Patton D, Dietrich B, Ho P, Bacwaden J, Ko C, et al.: A high-throughput Arabidopsis reverse genetics system. Plant Cell 2002, I 4:2985-2994.

120. Rosso MG, Li Y, Strizhov N, Reiss B, Dekker K, Weisshaar B: An Arabidopsis thaliana T-DNA mutagenized population (GABIKat) for flanking sequence tag-based reverse genetics. Plant Mol Biol 2003, 53:247-259.

I2I. Murashige T, Skoog F: A revised medium for a rapid growth and bioassays with tobacco tissue cultures. Physiologia Plantarum 1962, 15:473-497.

122. Image] - Image Processing and Analysis in Java [http:// rsb.info.nih.gov/ii/]

123. Sambrook J, Fritsch EF, Maniatis T: Molecular Cloning 2nd edition. Plainview, NY: Cold Spring Harbor Laboratory Press; 1989.

124. Frohman MA, Dush MK, Martin GR: Rapid production of fulllength cDNAs from rare transcripts-amplification using a single gene-specific oligonucleotide primer. Proc Natl Acad Sci USA 1988, 85:8998-9002

125. Smyth DR, Bowman JL, Meyerowitz EM: Early flower development in Arabidopsis. Plant Cell 1990, 2:755-767.

126. Shih MC, Heinrich P, Goodmann HM: Cloning and chromosomal mapping of nuclear genes encoding chloroplast and cytosolic glyceraldehyde-3-phosphate dehydrogenase from Arabidopsis thaliana. Gene 1991, 104:133-138.

127. Altschul SF, Gish W, Miller W, Myers EW, Lipman DJ: Basic local alignment search tool. I Mol Biol 1990, 2 I 5:403-410.

128. SMART [http://smart.embl-heidelberg.de]

129. PROSITE [http://www.expasy.ch/prosite/]

130. PSORT [http://psort.ims.u-tokyo.ac.jp/form.html]

|3I. PESTfind [https://embl.bcc.univie.ac.at/toolbox/pestfind/pestfindanalysis-webtool.htm]

132. PLANTSP [http://plantsp.genomics.purdue.edu]

133. MULTALIGN [http://bioinfo.genopole-toulouse.prd.fr/multalin/ multalin.html]

134. Corpet F: Multiple sequence alignment with hierarchical clustering. Nucleic Acids Res 1988, I 6: I0881-10890.

135. Xia X, Xie Z: DAMBE: software package for data analysis in molecular biology and evolution. I Hered 200I, 92:37I-373.

136. Schmidt HA, Strimmer K, Vingron M, von Haeseler A: TREE-PUZZLE: maximum likelihood phylogenetic analysis using quartets and parallel computing. Bioinformatics 2002, 18:502-504.

137. Seitz C, Eder C, Deiml B, Kellner S, Martens S, Forkmann G: Cloning, functional identification and sequence analysis of flavonoid 3'-hydroxylase and flavonoid 3',5'-hydroxylase cDNAs 
reveals independent evolution of flavonoid 3',5'-hydroxylase in the Asteraceae family. Plant Mol Biol 2006, 61:365-38I.

138. Page RD: TreeView: an application to display phylogenetic trees on personal computers. Comput Appl Biosci 1996, I 2:357-358.

139. CAMBIA [http://www.cambia.org]

140. Van Larebeke N, Engler G, Holsters M, Van den Elsacker S, Zaenen J, Schilperoort RA, Schell J: Large plasmid in Agrobacterium tumefaciens essential for crown gall-inducing ability. Nature 1974, 252:169-170.

141. Clough SJ, Bent AF: Floral dip: a simplified method for Agrobacterium-mediated transformation of Arabidopsis thaliana. Plant J 1998, 16:735-743.

142. NASC's Affymetrix Service: AffyWatch [http://affymetrix.ara bidopsis.info/AffyWatch.html]

143. Affymetrix [http://www.affymetrix.com]

144. Schoof H, Ernst R, Nazarov V, Pfeifer L, Mewes HW, Mayer KF: MIPS Arabidopsis thaliana Database (MAtDB): an integrated biological knowledge resource for plant genomics. Nucleic Acids Res 2004, 32:D373-376.

145. FunDaMiner - a functional analysis tool for expression data [http://mips.gsf.de/proj/express/]

146. Li C, Wong WH: Model-based analysis of oligonucleotide arrays: expression index computation and outlier detection. Proc Natl Acad Sci USA 200I, 98:31-36.

147. Bolstad BM, Irizarry RA, Astrand M, Speed TP: A comparison of normalization methods for high density oligonucleotide array data based on variance and bias. Bioinformatics 2003, 19:185-193.

148. Cleveland W: Robust locally weighted regression and smoothing scatterplots. J Am Stat Assoc 1979, 74:829-836.

149. Cleveland WS, Grosse E, Shyu WM: Statistical Models in S. Local Regression Models Wadsworth \& Brooks/Cole; 1992.

150. Dudoit S, Yang YH, Callow MJ, Speed TP: Statistical methods for identifying differentially expressed genes in replicated cDNA microarray experiments. In Technical Report Volume 578. Stanford University School of Medicine; 2000.
Publish with Bio Med Central and every scientist can read your work free of charge

"BioMed Central will be the most significant development for disseminating the results of biomedical research in our lifetime. "

Sir Paul Nurse, Cancer Research UK

Your research papers will be:

- available free of charge to the entire biomedical community

- peer reviewed and published immediately upon acceptance

- cited in PubMed and archived on PubMed Central

- yours - you keep the copyright

Submit your manuscript here:

http://www.biomedcentral.com/info/publishing_adv.asp
BioMedcentral 